\title{
Biological Activated Carbon Treatment Process for Advanced Water and Wastewater Treatment
}

\author{
Pengkang Jin, Xin Jin, Xianbao Wang, \\ Yongning Feng and Xiaochang $C$. Wang \\ Additional information is available at the end of the chapter
}

http://dx.doi.org/10.5772/52021

\section{Introduction}

The development of biological activated carbon (BAC) technology is on the basis of activated carbon technology development. Activated carbon which is used as a kind of absorption medium plays an important role in perfecting the conventional treatment process. Furthermore, activated carbon technology becomes one of the most mature and effective processes to remove organic contaminants in water. Removal of the odor in raw water can be regarded as the first attempt of activated carbon which can play a part in water treatment. The first water treatment plant in which granular activated carbon adsorption tank used was built in 1930 in Philadelphia, United States ${ }^{[1]}$. In the 1960-1970s, developed western countries started to use activated carbon technology in potable water treatment to enhance the removal of organic contaminants. By then, prechlorination was commonly used as the first step of activated carbon treatment. As the inflow of carbon layer contained free chlorine, the growth of microorganism was inhibited and no obvious biological activity showed in the carbon layer.

In order to improve the removal efficiency of refractory organics, especially the removal of precursors of DBPs, ozonation is commonly used in preoxidation before activated carbon process. The process which combines ozonation and activated carbon treatment was firstly put into practice in the year of 1961 at Amstaad Water Plant in Dusseldorf Germany. The successful trial in Dusseldorf soon arose great attentions from the engineering field in Germany as well as the Western Europe ${ }^{[2]}$. The advantages of microorganisms growing in the activated carbon layer was first affirmed by Parkhrust and his partners in 1967[3,4], this demonstration enabled the lengthening of the GAC's (Granular Activated Carbon) operation 
life to a great extent and Ozonation-Biological Activated Carbon technology was finally established. Since early 1970s, the study and application of Ozonation-Biological Activated Carbon treatment were conducted in large scales, among which the major ones are as the followings: the application in water plant of Auf dem Weule, Bremen Germany on a half productive scale ${ }^{[5]}$ and the application in Dohne water plant of Muelheim Germany on productive scale ${ }^{[6]}$. The successful application of Ozonation-Biological Activated Carbon technology in Germany is widely spread and used in neighboring countries, and the treatment itself was perfected gradually. In late 1970s, the treatment was popularized in Germany. In the year of 1976, the United States Environmental Protection Agency (US EPA) legislated that the activated carbon process must be adopted in potable water treatment process in urban areas with a population over 150,000. Among the water plants using activated carbon treatment, the most representative ones are: Lengg Water Plant in Switzerland ${ }^{[7]}$ and Rouen La Chapella Water Plant in France ${ }^{[8,9]}$, see Fig. 1. the flow diagram. The BAC process was firstly proposed in 1978 by G.W.Miller from the US and R.G.Rice from Switzerland ${ }^{[9]}$. In 1988, the quality requirements for potable water were improved in Japan and during the years 1988-1992, Kanamachi, Asaka, Kunijima and Toyono water treatment plants using the Ozonation-Biological Activated Carbon process were built ${ }^{[10]}$.

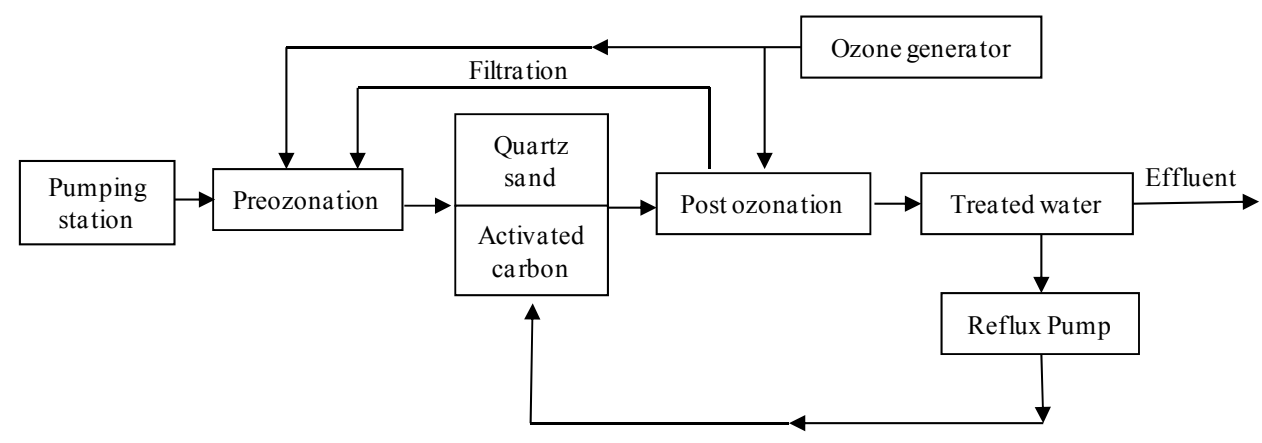

Figure 1. Flow diagram of the water plant in Rouen La Chapella

By now, BAC process has become the major process in advanced water treatment, which is commonly used in developed countries such as America, Japan, Holland, Switzerland, etc ${ }^{[1]}$. Meanwhile, the process is also widely used in industrial wastewater treatment as well as waste water reclamation. According to the prediction of experts, because of the increasing seriousness of the pollution in potable water and the strictness of requirements for potable water quality, the BAC process which combines the functions of physical-chemical absorption and biological-oxidation degradation, will become the conventional process widely used in potable water treatment plant ${ }^{[9]}$. 


\section{Composition of biological activated carbon process}

\subsection{Composition and application}

\subsubsection{Basic principles of biological activated carbon technology}

Biological Activated Carbon process is developed on the basis of activated carbon technology, which uses the synergistic effect of adsorption on activated carbon and biodegradation to purify raw water. Activated carbon has a high specific surface area and a highly developed pore structure, so it is characterized by its great effect on absorbing dissolved oxygen and organics in raw water. For Biological Activated Carbon technology, activated carbon is used as a carrier, by accumulating or artificially immobilizing microorganisms under proper temperature and nutrition conditions, the microorganisms will reproduce on the surface of the activated carbon and finally form BAC, which can exert the adsorption and biodegradable roles simultaneously[11]. The Biological Activated Carbon technology consists of the interaction of activated carbon particles, microorganisms, contaminants and the dissolved oxygen, in water solution. Fig. 2. shows the simplified model that how the 4 factors interact with each other ${ }^{[12]}$. The relationship between the activated carbon and contaminants is simply the effect of adsorption of activated carbon, and the reaction depends on the properties of the activated carbon and contaminants. Meanwhile, the activated carbon can adsorb DO and microorganisms which were adsorbed on the surface of activated carbon, feed on DO will biodegrade contaminants. In brief, by the interaction of these 4 factors, the purpose for removing contaminant from raw water can be achieved by adopting the biological activated carbon.

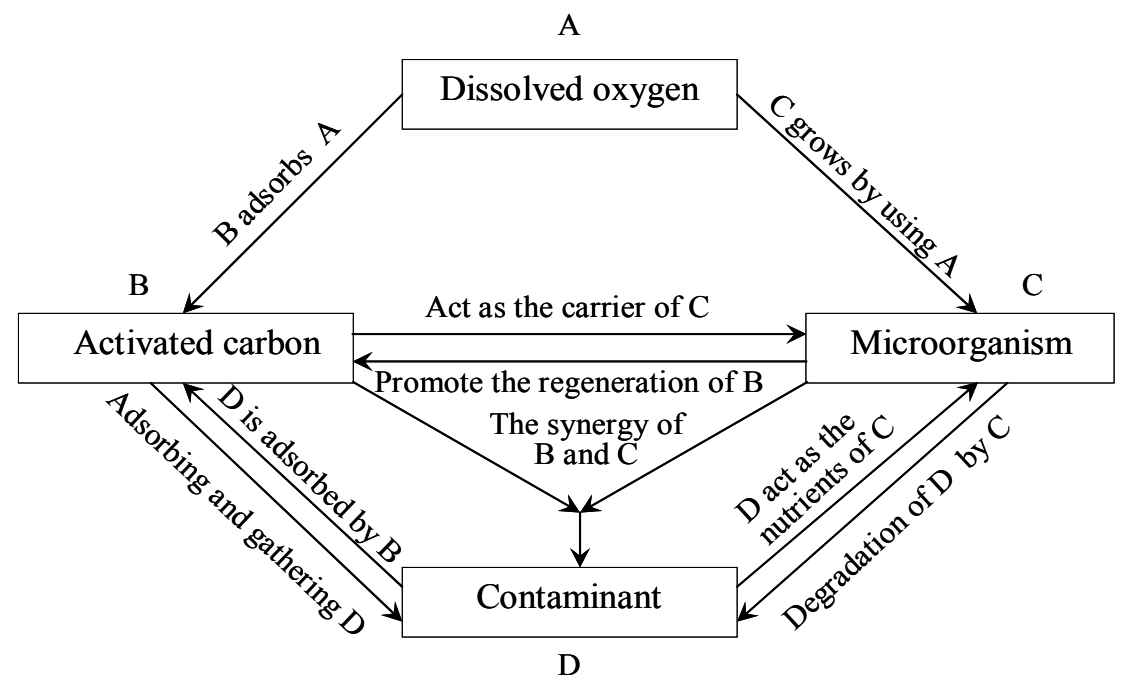

Figure 2. Simplified interaction model of factors in BAC process 


\subsubsection{Application fields and the typical process flow of biological activated carbon technology}

At present, the application of BAC technology is mainly focused on 3 aspects: the advanced treatment for potable water and the industrial waste water treatment. The typical process of the advanced treatment for drinking water and sewage reuse is shown in Fig. 3. All of the three processes are based on conventional coagulation-sedimentation-filtration way. They are distinct from the different positions, the two processing points, to import ozone and the activated carbon. In process a, the activated carbon procedure is between sedimentation and filtration. The outflow from the activated carbon layer will bring some tiny carbon particles and fallen microorganisms, which will be removed by a sand filter in the end. To improve the filtration efficiency, chlorination and enhanced coagulation were done firstly before this procedure. In this process, the quality of the outflow is guaranteed with a relatively higher ozone dosage. While in Process b, the ozonation and the activated carbon procedure is done after the filtration, by which, the ozone depleting substances will be removed therefore a lower ozone dosage than Process a. However, micro carbon particles and microorganisms which leap out of the activated carbon layer will have an undesirable impact on the quality of the outflow, so the frequent backwash on the activated carbon layer is required. Process c is characterized by a two-level ozone procedure, which means to put ozone separately before and after the sand filtration, the remaining procedures are same with Process $b$. A lower ozone dosage before the sand filtration is used to improve the filtration efficiency ${ }^{[13]}$.

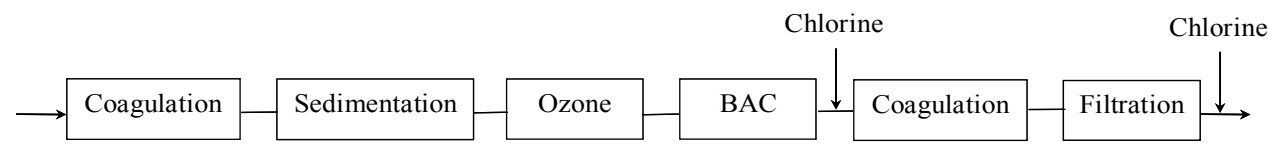

(a)

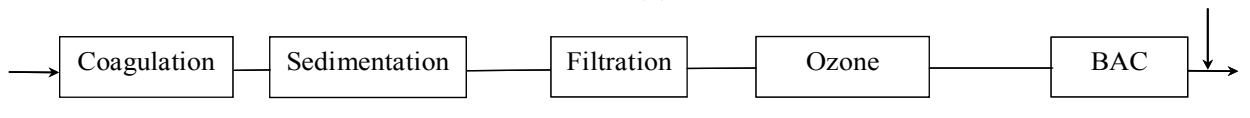

(b)

Chlorine

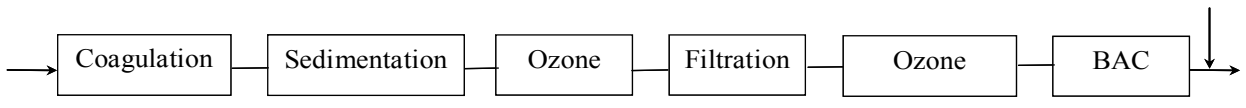

(c)

Figure 3. Typical processes of BAC

Also, it is widely used in industrial waste water treatment, such as printing and dyeing wastewater, food processing wastewater, pharmaceutical wastewater, etc. Throughout the typical process of BAC treatment, it is obvious that these three technological processes are related to oxidation-BAC technology. Compared with conventional bio-chemical technology, contact oxidation-BAC process has its unique characteristics. Firstly, contact oxidation can remove organics and ammonia-nitrogen, reduce odor and the amount of DBPs precursor, as well as to reduce the regrowth possibility of bacteria in pipeline, so as to increase the biological stability. Secondly, contact oxidation can reduce the processing load 
of BAC treatment, and, to some extent, increase the working life and capacity of remaining filtration and BAC, which ensure a safer, reliable outflow ${ }^{[14-17]}$.

\subsubsection{Basic operational parameters of BAC process $^{[18]}$}

To design a BAC system, it is necessary to comprehend the characteristics of water quality, water amount and some certain index of water treatment. First of all, the experiments on the adsorption performance and biodegradability of the waste water are indispensable. Then, according to the result of static adsorption isotherms experiment on the raw water, the appropriate kind of the activated carbon can be chosen, and on the basis of dynamic adsorption isotherms experiment, the basic parameters can be determined. Ultimately, according to the process scale and condition of the field, BAC adsorption devices and its structure as well as supplementary equipment can be determined.

The activated carbon used in BAC process, should be highly developed in the pore structure, especially for the filter pores. Quality of the outflow is directly influenced by the filtering velocity, height of the carbon layer, the retention period and the gas-water ratio. In practice, the general filtering rate is $8-15 \mathrm{~km} / \mathrm{h}$. Retention period: According to the different pollutants, the general retention period should be 6-30 min; when the process is mainly removing smelly odor from the raw water, the period should be $8-10$ min; when the process is mainly dealing with $\mathrm{CODMn}_{\mathrm{Mn}}$ the period should be 12-15 min. Gas-water ratio: As to aerobic microorganism, sufficient DO in the activated carbon layer is needed. Generally, DO $>1 \mathrm{mg} / \mathrm{L}$ is proper in the outflow, therefore the design is based on a (4-6):1 gas-water ratio, specific details are based on the height of the carbon layer and concentration of organic contaminants. Generally, the thickness of the activated carbon layer is $1.5-3 \mathrm{~m}$, which is determined by the leaping curve of the activated carbon. The growth of microorganisms and suspended solids brought by the inflow on the long-term operating biological carbon bed may block the carbon layer, and the biofilm on the surface of the activated carbon is unlikely to be discovered by naked eyes. Once the thickness is out of limits, the adsorption ability of the activated carbon will be affected undesirably. Therefore, the carbon layer should be washed periodically. Related parameters for backwash are shown in table 1 .

\begin{tabular}{c|c|c|c}
\hline \multicolumn{2}{c}{ Backwash type } & \multicolumn{2}{c}{ Granular activated carbon grade } \\
\cline { 3 - 4 } & & $2.38 \sim 0.59 \mathrm{~mm}$ & $1.68 \sim 0.42 \mathrm{~mm}$ \\
\hline \multirow{4}{*}{$\begin{array}{c}\text { Air-water } \\
\text { backwash }\end{array}$} & Water wash intensity $\left[\mathrm{L} /\left(\mathrm{m}^{2} \cdot \mathrm{s}\right)\right]$ & 11.1 & 6.7 \\
\cline { 2 - 4 } & Water wash interval $(\mathrm{min})$ & $8 \sim 10$ & $15 \sim 20$ \\
\cline { 2 - 4 } & Air wash intensity $\left[\mathrm{L} /\left(\mathrm{m}^{2} \cdot \mathrm{s}\right)\right]$ & 13.9 & 13.9 \\
\cline { 2 - 4 } & Air wash interval $(\mathrm{min})$ & 5 & 5 \\
\hline \multirow{2}{*}{$\begin{array}{c}\text { Water wash } \\
\text { and surface }\end{array}$} & Water wash intensity $\left[\mathrm{L} /\left(\mathrm{m}^{2} \cdot \mathrm{s}\right)\right]$ & 11.1 & 6.7 \\
\cline { 2 - 4 } wash & Water wash interval $\left(\mathrm{min}^{2}\right)$ & $8 \sim 10$ & 1.67 \\
\cline { 2 - 4 } & Air wash intensity $\left[\mathrm{L} /\left(\mathrm{m}^{2} \cdot \mathrm{s}\right)\right]$ & 1.67 & 5 \\
\cline { 2 - 4 } & Air wash interval $(\mathrm{min})$ & 5 & \\
\hline
\end{tabular}

Table 1. Backwash parameters for activated carbon 


\section{2. $\mathrm{O}_{3}-\mathrm{BAC}$ process and the evaluation of ozonation}

\subsubsection{Mechanism and characteristics of $\mathrm{O}_{3}-B A C$ process}

In practice, there are still some problems when BAC technology is used alone, for example, some difficult biodegradable materials can not be removed effectively and the working life of BAC would be reduced. Meanwhile, in order to ensure the safety of water distribution system, disinfection is indispensable after biological treatment. When chlorine treating potable water is used, large amounts of halogenated organic byproducts will be produced during the reaction between the organics and the chlorine. Among those byproducts, THMs, HAAs, etc., are carcinogenic. Therefore, before BAC treatment, preozonation, the $\mathrm{O}_{3}-\mathrm{BAC}$ Process, is widely used, which concludes 3 procedures: ozonation, adsorption effect of activated carbon and biodegradation ${ }^{[19]}$. When $\mathrm{O}_{3}$-BAC Process is used, organic will be firstly oxidized into small degradable molecules by strong oxidation of ozone, then the small degradable molecules will be adsorbed onto the activated carbon and degraded by microorganism, simultaneously the oxygen discomposed from ozone will enhance the level of DO, which makes DO in raw water be saturated or approximately saturated, which in turn, provides necessary condition for biodegradation ${ }^{[20-25]}$. Fig. 4 . shows a simplified model of mutual effects among the main factors during $\mathrm{O}_{3}-\mathrm{BAC}$ Process ${ }^{[26]}$.

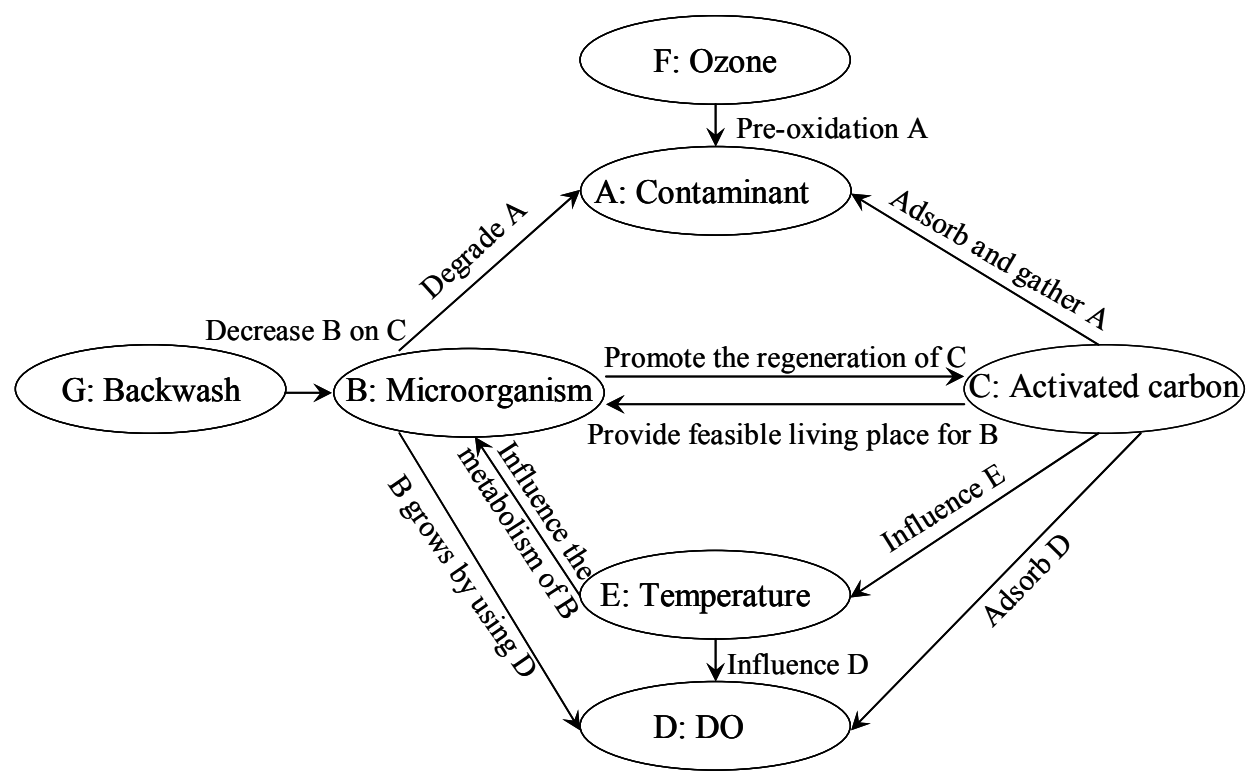

Figure 4. Model scheme of $\mathrm{O}_{3}-\mathrm{BAC}$ 


\subsubsection{Effect of ozonation on molecule weight distribution and the molecule structure of organic matters ${ }^{[27-30]}$}

\subsubsection{Effect of ozonation on molecule weight distribution of organic matters}

Pre-ozonation can change the properties and structures of organics in raw water. By using high performance liquid chromatography (HPLC), the variations of molecule weight before and after ozonation is studied, the result is shown in Fig. 5. As shown, the molecule weight mostly distributed within a range of 2000-6000, and 2000-3000 after the ozonation, the amount of organics with a relative molecule weight under 500 is increased dramatically. This indicates that macromolecules are in a high proportion in raw water, but after the ozonation, the proportion of macromolecular organic matter decreases while small molecule weight organics increases, which implies that part of the intermediate material from ozonation is namely the increased small molecular weight organic matter.

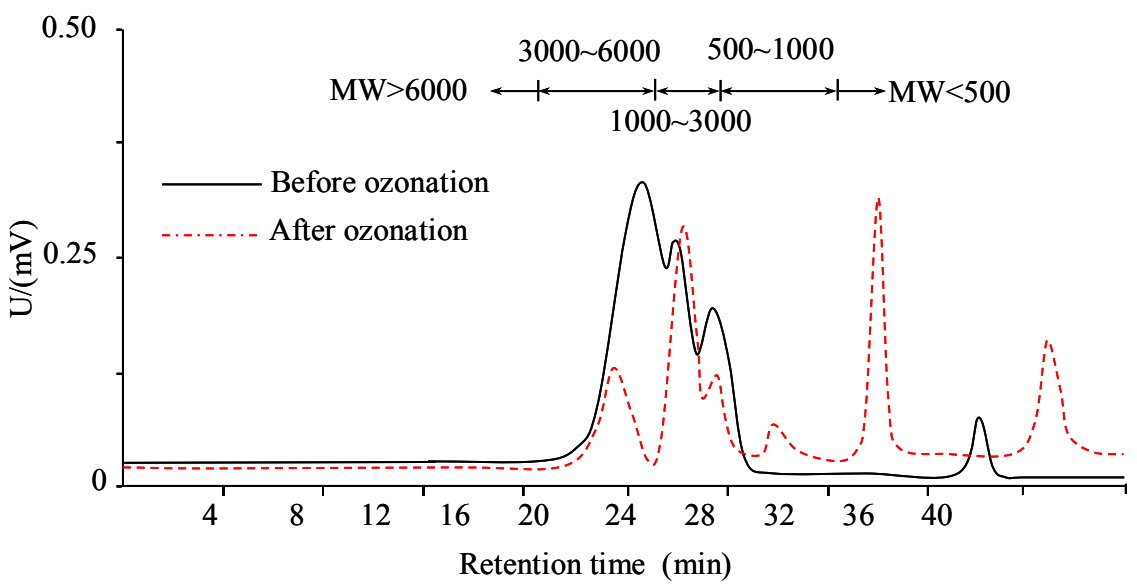

Figure 5. Molecular weight distribution before and after ozonation

\subsubsection{Effect of ozonation on the structure of organic matters}

In this part, Gas Chromatography-Mass Spectrometer (GC-MS) is used to analyze the structure of organics in raw water before and after ozonation, results are shown in Fig. 6. As shown, the organics in raw water are mainly aromatic hydrocarbons, chain hydrocarbon and aliphatic organics; after ozonation, the amount of aliphatic organic matters increases significantly and the amount of esters tend to increase too, which indicate that part of the aromatic organics are oxidized into organics of oxygen-containing groups, such as fatty acids, carboxylic acids and esters. 


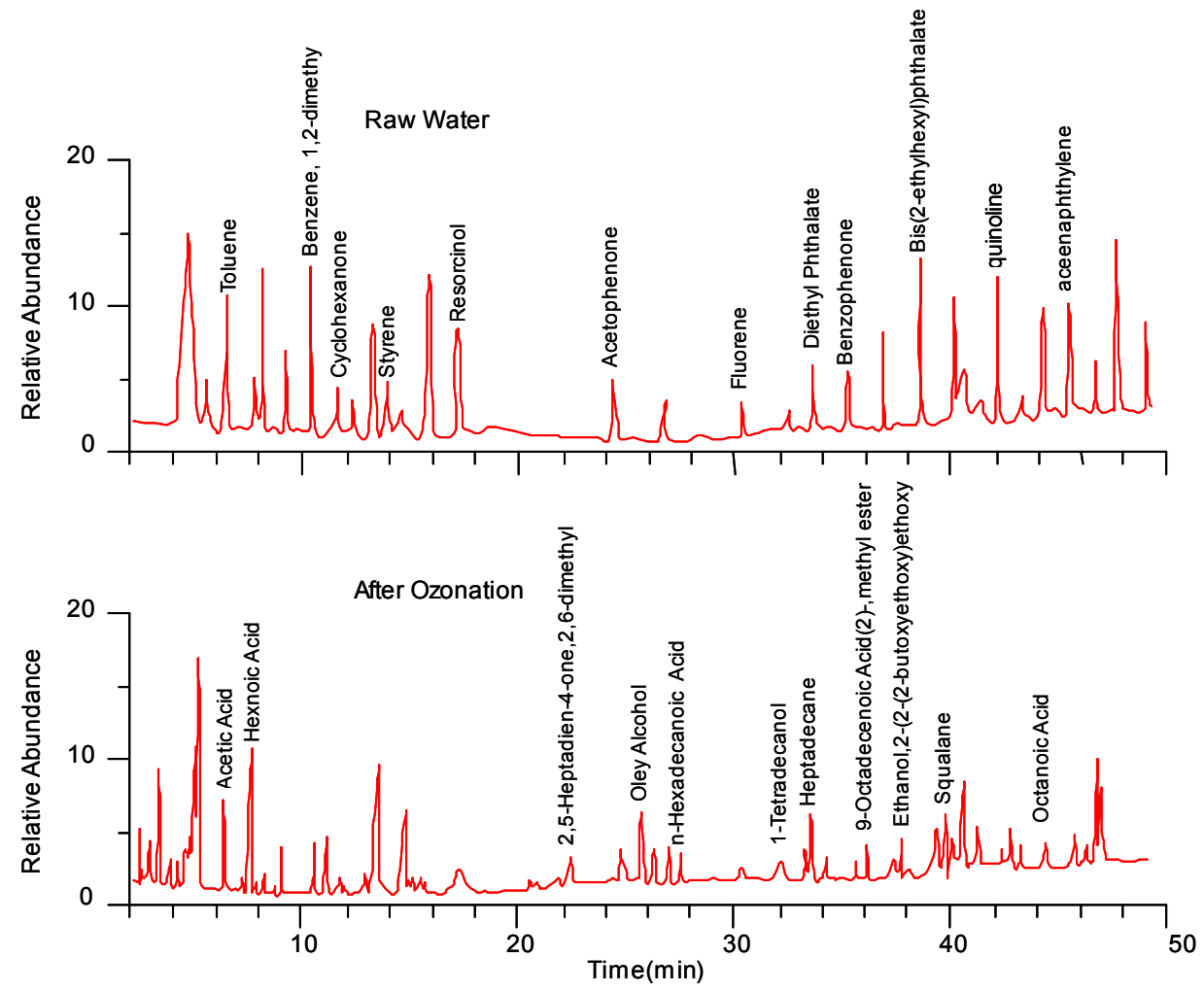

Figure 6. GC-MS chromatogram of raw water before and after ozonation

\subsubsection{Improvement of biochemical properties of organics by ozonation}

During the process of ozonation, complex chemical reactions occurred between ozone and organics. Pre-ozonation can change the biodegradability of organics in water, so generally BDOC is used as an index to analyze the water after ozonation. Fig. 7. shows the variation tendency of DOC, BDOC and BDOC/DOC in raw water after ozonation. The result indicates that after ozonation, DOC in raw water is seldom removed while BDOC increases obviously, among which the ratio of BDOC/DOC increases from $11.6 \%$ to $26.4 \%$. After ozonation, the biodegradability of organics in water is highly improved, which enhance the biodegradation of BAC filter bed in the following procedure. 


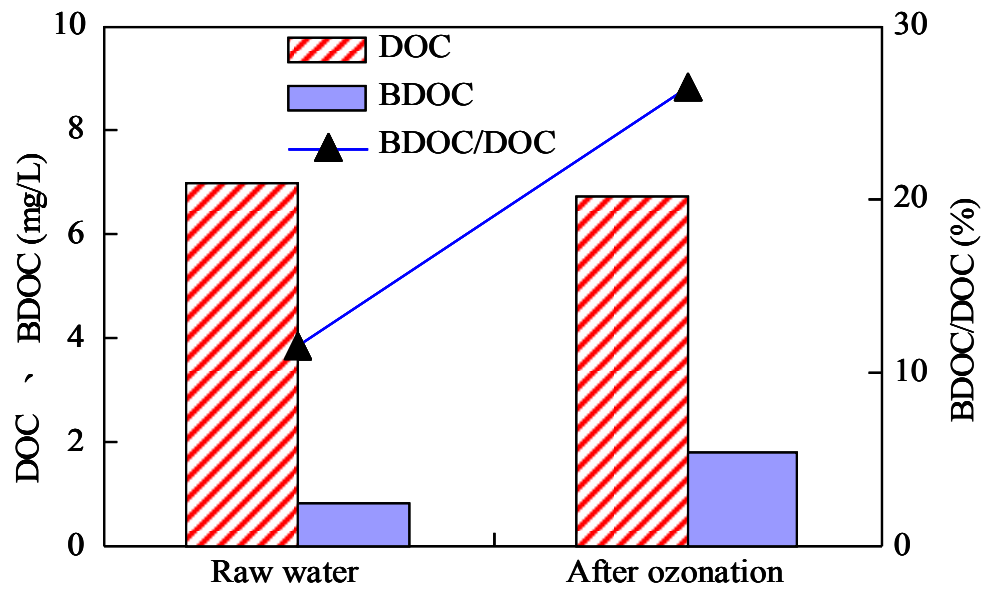

Figure 7. Variations of DOC, BDOC, BDOC/DOC before and after ozonation

\subsubsection{Improvement of ozonation on biodegradability of organic matters}

Relevant researches indicate that ozonation can change the molecule weight distribution, structures and the biodegradability of the organics in water. To thoroughly understand the role organics degradation and ozonation played in the whole process, degradation of the organics without dosage of ozone shall be taken for comparison. Variation of DOC, BDOC, $\mathrm{BDOC} / \mathrm{DOC}$ on each layer of BAC bed with ozone or without ozone are both reviewed, the result is shown in Fig. 8 and 9.

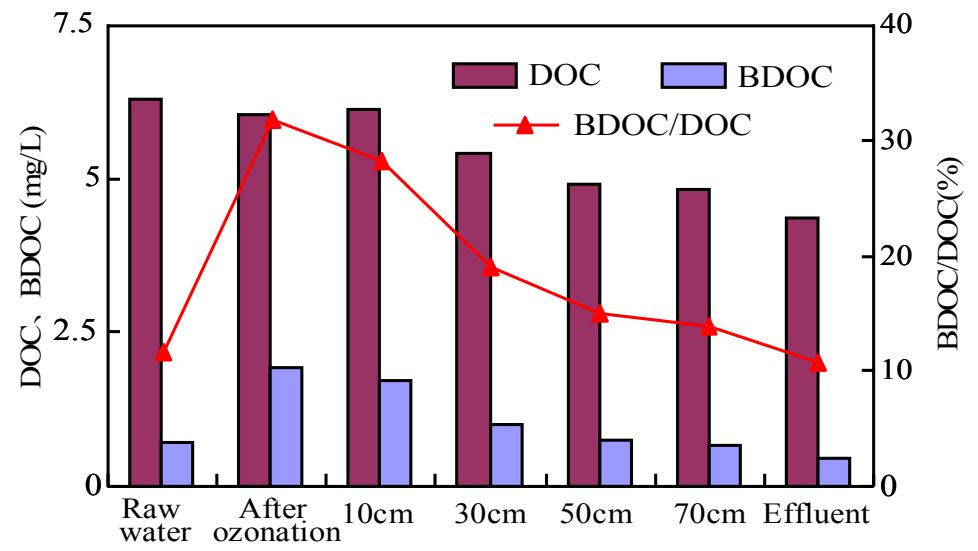

Figure 8. Degradation effects of different layers in BAC bed with ozone pretreatment 


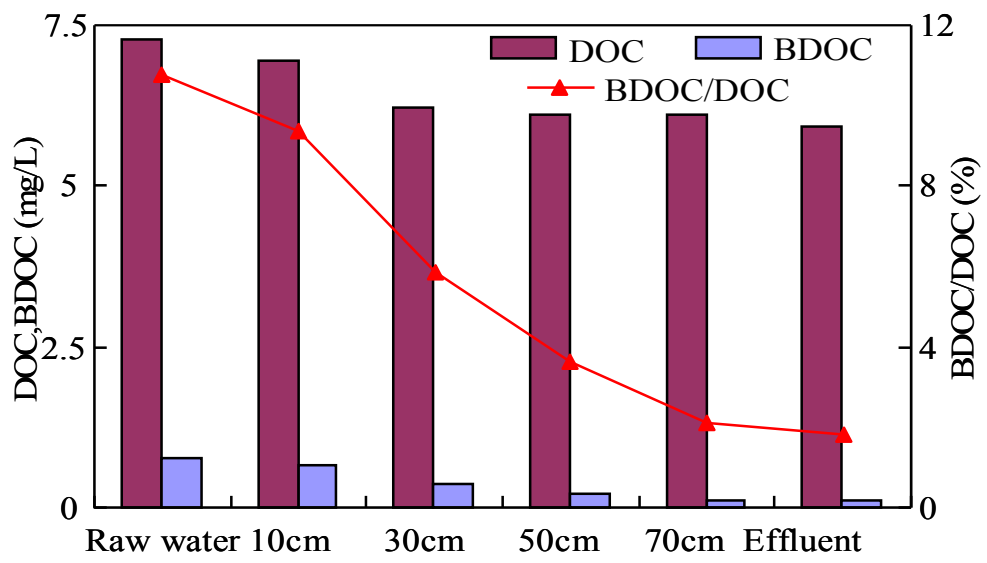

Figure 9. Degradation effects of different layer in BAC bed without ozone pretreatment

As shown in the figure, no matter the ozone is added or not, the tendencies of organics degradation in BAC bed are similar. With the addition of ozone, the properties of organics after ozonation will change, and the amount of BDOC increased. Viewed from aspect of general efficiency of removal, with the addition of ozone, the removal rate of DOC is $31 \%$, while $18 \%$ removal rate without ozone.

According to further analysis of the data in Fig. 9, results show that, degradation efficiency of DOC without ozone is $18.4 \%$, DOC of outflow from the BAC bed is $5.92 \mathrm{mg} / \mathrm{L}$ and the removal quantity of DOC is $1.351 \mathrm{mg} / \mathrm{L}$, in which the removal quantity of BDOC is 0.676 $\mathrm{mg} / \mathrm{L}$. In this case, the removal of NBDOC takes a proportion of $49 \%$ in the total removal of DOC. Bio-degradation mainly removes BDOC in organics, while adsorption mainly removes NDOC and part of BDOC. That is to say, for BAC process absorption takes a proportion of $49 \%$ during the entire removal process without dosage of ozone. Similarly, to analyze the data shown in Fig. 8, the variation of adsorption and bio-degradation effects during the organic degradation process whether added with ozone or not are shown in Table 2 .

\begin{tabular}{ccc}
\hline BAC/DOC Degradation & With Ozone Pretreatment & Without Ozone Pretreatment \\
\hline Adsorption & $35 \%$ & $>49 \%$ \\
Biodegradation & $65 \%$ & $<51 \%$ \\
\hline
\end{tabular}

Table 2. Effect of ozonation on adsorption and biodegradation during BAC process

According to Fig. 3, on the aspect of the adsorption and bio-degradation in DOC removal process, ozonation can enhance the bio-degradation effect greatly, while exert a negative effect on adsorption of activated carbon. 


\section{Characteristics of microorganisms and mechanisms of pollutants degradation in BAC filtration}

\subsection{Immobilization of microorganisms on the carriers}

At present, most of the BAC process is based on ordinary BAC which is naturally formed during the long-term operation. Due to the complexity of biofacies on its surface, the greatest deficiency of conventional BAC is that dominant microflora are hard to be formed, which has been improved by the rapid development of modern biology technology and the technology known as immobilization biological activated carbon (IBAC). The basic principle of IBAC is screening and acclimation dominant biocommunity from nature, followed by immobilizing the community on activated carbon, to enhance the efficiency and rate of degradation. Meanwhile, dominant biocommunity should be nonpathogenic and has strong antioxidant capacity and enzyme activity which enable the growing and reproducing under poor nutrition environment. Therefore, the effect of biodegradation after activated carbon adsorption saturation is highly improved by IBAC ${ }^{[31-32]}$.

\subsubsection{Intensification and immobilization of dominant biocommunity}

Dominant microflora is selected by artificial screening and domesticating or directive breeding through biological engineering technology. Separation is the first step for getting dominant biocommunity. However, the filtered biocommunity may contain pathogenic bacteria, or with low-rated growth or high requirements for nutrition, which make it inadaptable for practical application, therefore, preliminary screening is indispensable for guaranteeing the security of selected bacterial strains. Due to the high complexity of biofacies, various species but less nutrition matrix in water, low-activated bacterial strain screened. This situation makes a relatively high disparity from the effective biological treatment. Therefore, intensification on selected bacterial strain is necessary. The process of intensification is actually the process of induction and variation of biocommunity. By changing nutritional conditions repeatedly, the bacterial strain will gradually adapt to the poor nutrition environment in fluctuation, so that the bacterial strain immobilized on activated carbon can preserve a strong ability for biodegradation ${ }^{[33]}$.

During IBAC treatment, the process of microorganisms immobilizing is of great complexity, which is not only related to various acting forces, but also involves microorganism growth as well as the ability for producing extracellular and external appendages ${ }^{[34]}$. DLVO theory can give a better explanation that how bacteria are attached, when bacteria are regarded as colloidal particles ${ }^{[35-37]}$. Although there is a relatively high repulsive force during the process when the bacteria approaching to the activated carbon, the bacteria will ultimately contact with the activated carbon under the bridging effect of EPSs ${ }^{[38]}$. The bacteria may take advantage of the bridging effect with surficial particles, which enables the attachment of itself with filter materials at secondary extreme point in accordance with the theoretical level diagram of DLVO theory, rather than by the certain distance or overcoming the necessary energy peak as that of non-biological particle ${ }^{[39]}$, see Fig. 10. for details. Although there are 
various ways to immobilize microorganisms, and any method with a limitation for freeflowing of microorganisms can be used to produce and immobilize microorganisms, an ideal and universal application way for immobilizing microorganisms is still not available. There are 4 common methods of immobilization, see Table $3^{[40-42]}$ for details.

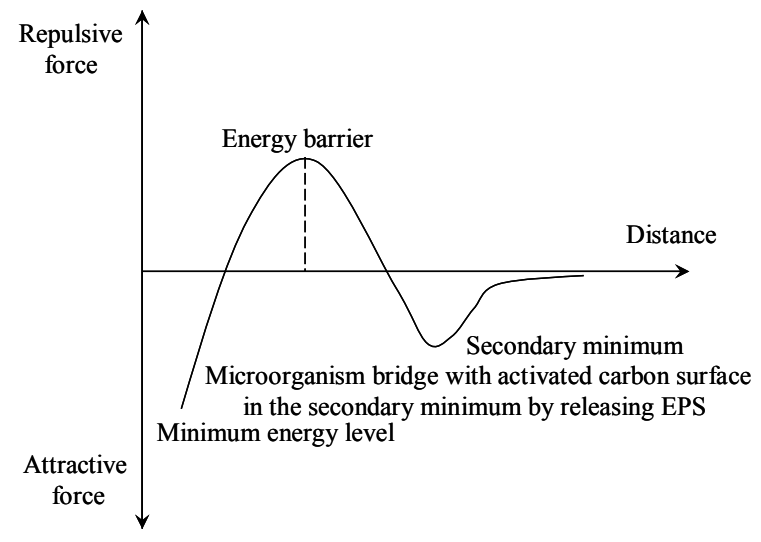

Figure 10. Total potential energy for express microbial immobility on activated carbon based on DLVO theory and short-range force

\begin{tabular}{ccccc}
\hline Property & Covalention & Adsorption & Covalent & Embedding \\
\hline Implementing difficulty & Moderate & Easy & Difficult & Moderate \\
Binding force & Strong & Weak & Strong & Moderate \\
Active surface & Low & High & Low & Moderate \\
Immobilized cost & Moderate & Low & High & Low \\
Viability & No & Yes & No & Yes \\
Applicability & Bad & Moderate & Bad & Good \\
Stability & High & Low & High & High \\
Carrier regeneration & Unable & Able & Unable & Unable \\
Steric hindrance & Larger & Small & Larger & Large \\
\hline
\end{tabular}

Table 3. Comparison of the methods for immobilization of common microorganisms

\subsubsection{Growth characteristics of dominant microflora on the surface of activated carbon ${ }^{[43]}$}

In the early period of IBAC operation, the results for the biomass and biological activity on the surface of activated carbon monitored continuously are shown in Fig. 11. and Fig. 12.. At initiating stage, there is a rapidly dropping period for the dominant micoflora biomass on activated carbon. As time goes by, dominant biocommunity becomes steady gradually. At initial stage of BAC process, the biomass on activated carbon surface is in little, different from IBAC process, therefore, the microbial action can be ignored basically. During this period, variation of the biological activity for dominant biocommunity is similar to the change of biomass. 


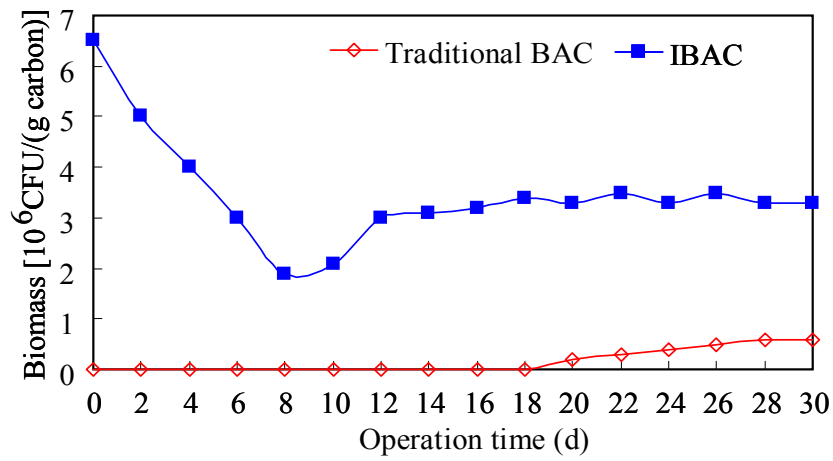

Figure 11. Variations of biomass on activated carbon

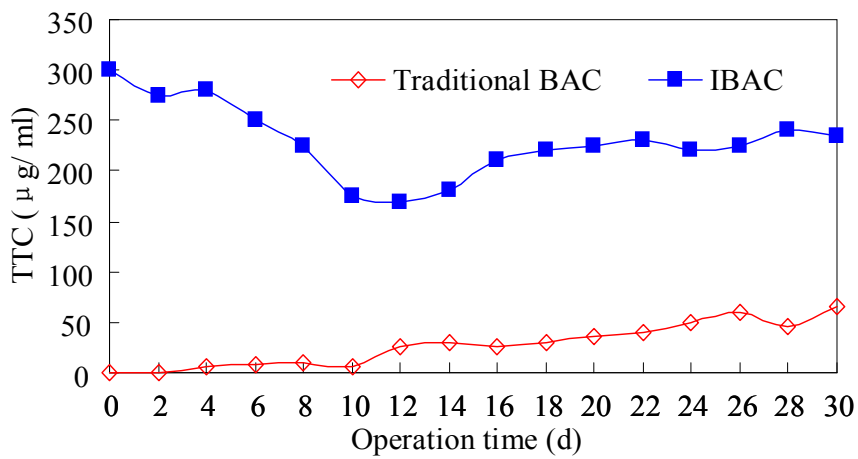

Figure 12. Variations of biological activity in two activated carbon processes

The variations of biomass and biological activity of microbe on activated carbon in longterm operation process are shown in Fig. 13. As shown, the biomass on carbon bed remains constant which mainly because of a gradual adaptation process of dominant biocommunity to the water, during which the adhesive ability of the dominant biocommunity is relatively low. Therefore microbe on the upper layer will be washed into the lower layer of the activated carbon, which has a beneficial effect on the reasonable distribution of the dominant biocommunity. With the extension of operating time, the dominant biocommunity will be adapted to the environment gradually. Meanwhile, due to the higher concentration of nutrient media in the upper layer, the biomass on the upper layer will be greatly increased and remains constant for a long period. Being different from the constancy of biomass on activated carbon, the biological activities in the upper and the lower layers of IBAC bed have a decreasing tendency as operation time goes. Shown from the result of PCR-DGGE, this reduction is mainly caused by the continuous incursion of the native bacteria with low capacity. 


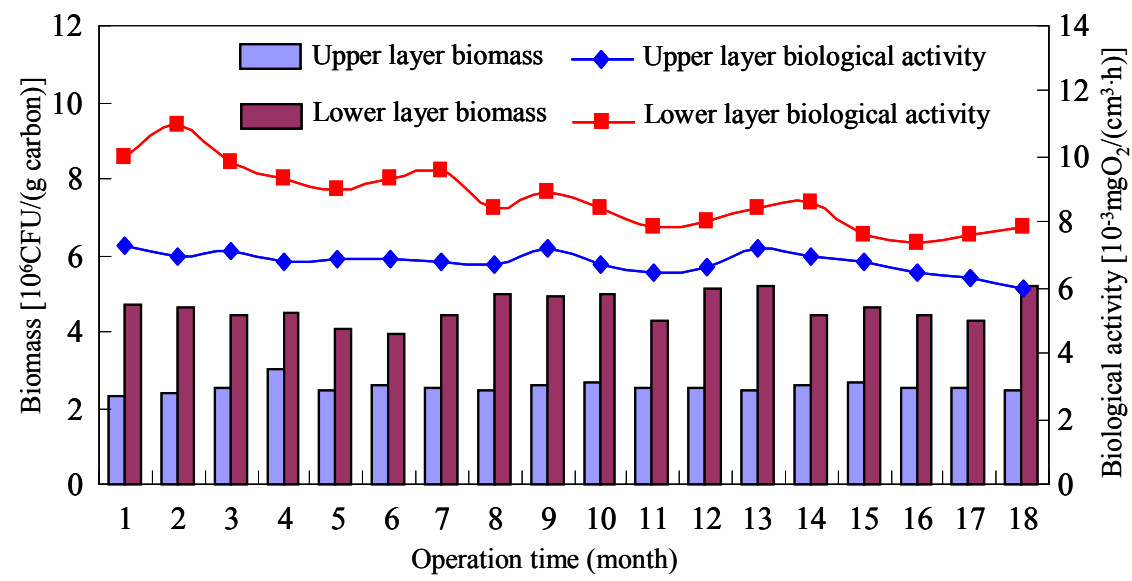

Figure 13. Variation of biomass and biological activity on activated carbon

\subsubsection{Influencing factors of dominant microflora biological stability}

During the IBAC process, the biological stability of the dominant microflora is the key factor to ensure an effective operation. However, the factors including the property of the activated carbon, the dosage of ozone, hydraulic retention time and the condition of backwash all have impacts on the dominant biocommunity at different levels. When all combined influences considered, the main factors of the activated carbon effects on the stability of dominant biocommunity are the distribution of pores in activated carbon, the physical and mechanical properties as well as its chemical property, among which molasses value is the primary controlling index [44-46]. Although ozonation may improve the biodegradability of water, provide an oxygen-rich condition and reduce the incursion of undesirable bacteria, as well as enhance the biological activity of dominant biocommunity, however, relevant research shows that when the residual ozone reaches even over $0.1 \mathrm{mg} / \mathrm{L}$ in the inflow of IBAC system, a restrain on dominant biocommunity will be shown ${ }^{[4]}$. By increasing the contact time of the dominant microflora with organics, the adsorption and mass transfer of organics can be enhanced, thus the biological activity of the dominant biocommunity is improved. Generally, the most appropriate retention time is about 20 $\min ^{[48]}$. The backwash step has an impact on the biological activity of the dominant biocommunity, which makes biological activity of the community in each layer rapidly decreases from the normal level to the minimum, but still remains in a certain range. After the sharp cutoff, the biological activity of the community will recover at normal level rapidly. Meanwhile, the intensity of backwash and its time also have a great impact on biological stability ${ }^{[49]}$. 


\subsection{Characteristics of the biocommunity structure and distribution}

The huge superficial area and rich porosity of the activated carbon provide a preferable habitat for microbe and prompt the formation of biological membrane. According to the research, the synergy effects of activated carbon adsorption and biodegradation enable $\mathrm{O}_{3}-$ BAC to realize the removal of organics in water (see 3.4 for details). Meanwhile, as the duration of BAC use gets longer, the action of organisms plays a more and more predominant role ${ }^{[50,51]}$. Quite a few researchers point out that the range of bacteria using the activated carbon as a carrier to habitat includes aerobic, anaerobic and facultative bacteria ${ }^{[2,53]}$. In this chapter the variation of bacteria communities and the characteristic of the community structure will be discussed, and the system chosen here is down-flow $\mathrm{O}_{3}-$ BAC system shown in Fig. 14.

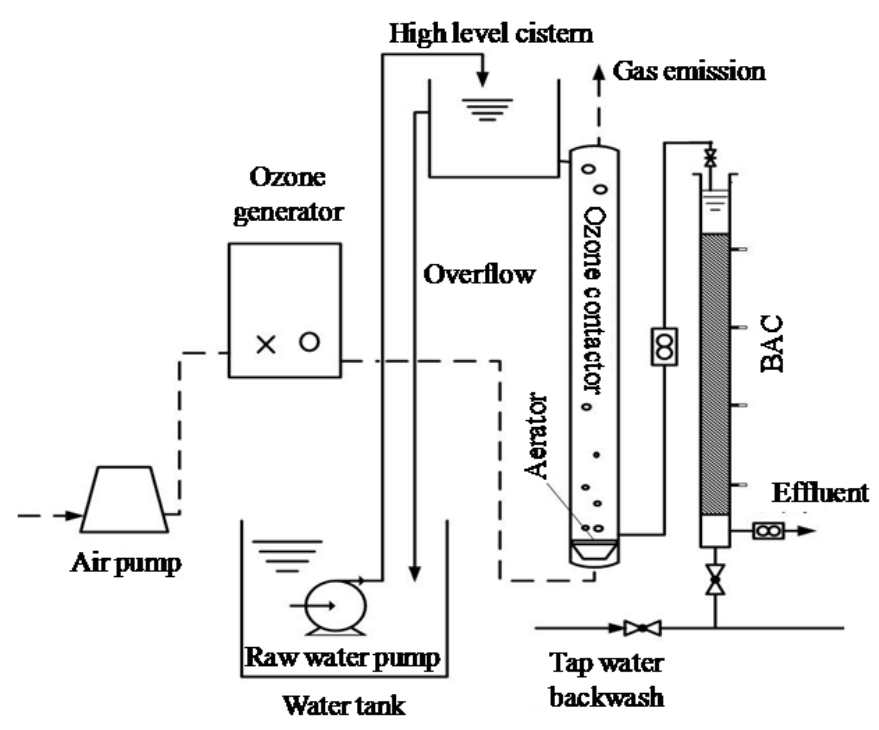

Figure 14. Pilot test setup

\subsubsection{Characteristics of strain distribution}

Various kinds of strains exist in BAC column (see Fig. 15). The picture demonstrates, (L-R), 4 sections $(1,2,3$ and 4) from top to bottom of the down-flow BAC layers respectively. The shadows in the finger prints represent different strains, and the numbers of the shadow zones represents the numbers of strains, while every shade represents a kind of strain, so the different shades represent the number of species indicatively. Fig. 15. shows that the number of shadow zones is 16 that can be discovered obviously, which indicates that the number of strains exist in BAC column is 16 according to detection. Meanwhile, along the carbon layer from top to bottom of the picture (L-R), there are 7 shadow zone shades turning weak gradually, which indicates that with the increasing of the carbon layer depth, these strain kinds are reduced gradually. There are 5 shadow zone shades turning darker, 
which indicates that with the increasing of carbon layer depth, these strain kinds increase. Another 4 zones remained do not exist in every section, among which the quantity of one kind of strain is not changing, 2 kinds of strains only exist in the upper side of the activated carbon, while only 1 strain exists in the bottom of the activated carbon bed.

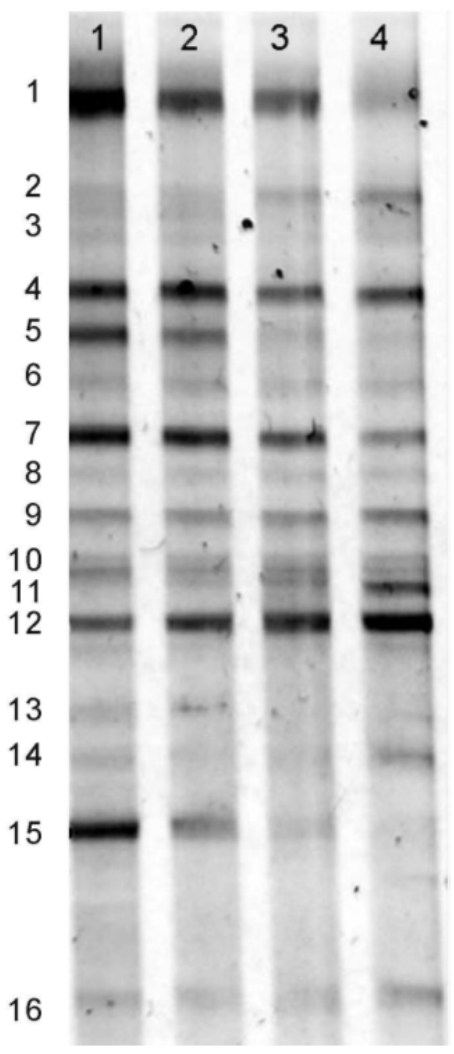

Figure 15. Analysis results of PCR-DGGE

\subsubsection{Characteristics of biomass distribution}

The growth of microorganism in BAC bed can be divided into three phases: logistic phase, stable phase and decayed phase (see Fig. 16). In the first period, microbe multiplies. In the initial period of biofilm formation, microbe quantity is rather low, and the highest biomass only reaches $70 \mathrm{nmolP} / \mathrm{gC}$. When the water temperature is proper and the inflow contains a lot organics, biological multiples rapidly. After one and half a month of the reduction period, it reaches the stable phase. Generally, in this phase, the concentration of the substrate declines, which means the degradation rate is rather high; DO consumption is also in large amount. In the second phase, microbe grows stably. After a period of cultivating when the water temperature is proper, the microbe basically reaches a state of stability, in which the microbe quantity maintains in the range of $450-520 \mathrm{nmolP} / \mathrm{gC}$ and the microbe 
grows normally. Meanwhile, the removal effect on pollutants in water is also steady, and at this point, the eco-system of BAC bed is relatively steady. This phase is characterized by equilibrium between biological membranes of new cells and the loss of membranes causing by physical force. In the decay phase, when water temperature as well as other conditions varies fiercely, the microbe quantity decreased rapidly and entering the final phase, in which degradable rate decreased, quality of outflow will be worsen.

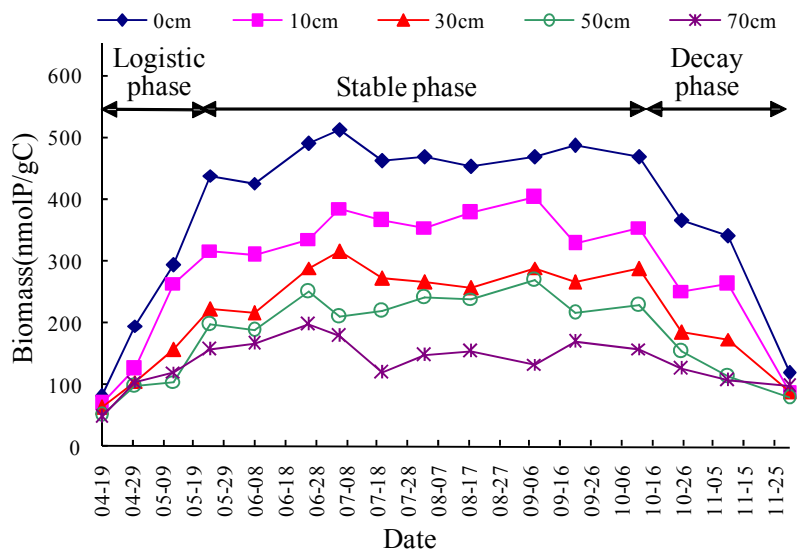

Figure 16. Variation of biomass in BAC Bed at different time

As the substrate is oxidized and degraded by the microbe membrane from top to bottom, the concentration decreased gradually, lead to the decline of available organic concentration and the poor nutrition condition of the microbe. Besides, it's also related to DO concentration. DO distribution in BAC column is gradually decreased from top to bottom, the lower it goes on the carbon bed, the fewer the available DO for microbe to reproduce, so does the biomass. Thus, the biomass distribution in BAC bed shows a feature of gradually decreasing from top to bottom (see Fig. 17).

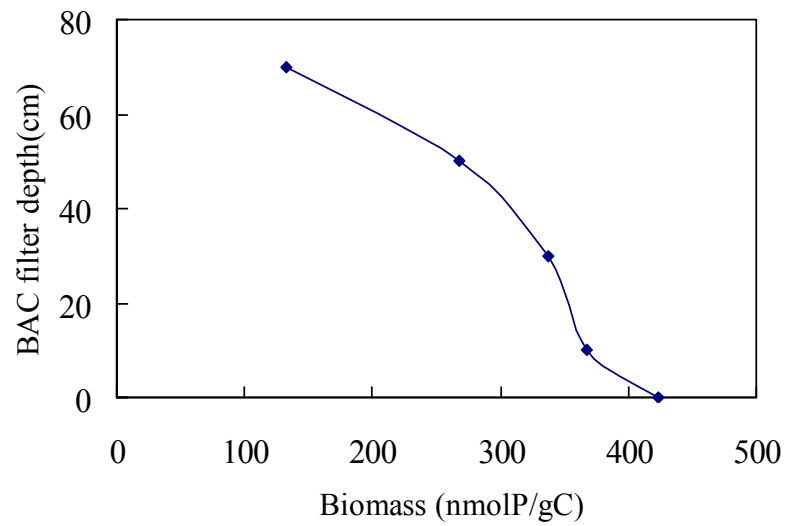

Figure 17. Variation of biomass along at different time BAC filter depth 


\subsubsection{Characteristics of biocommunity distribution}

For down-flow BAC bed, though there was a decreasing tendency of bacteria adsorbed on activated carbon from top of the carbon layer to the bottom, the variation tendencies of ammonifying bacteria, anti-vulcanization bacteria and denitrifying bacteria are not exactly the same, among which ammonifying bacteria showed a decreasing tendency from top of the carbon layer to the bottom; anti-vulcanization bacteria showed an increasing tendency from top of the carbon layer to the bottom reaching a steady quantity; while denitrifying bacteria which located higher than $30 \mathrm{~cm}$ of the carbon layer showed a gradual increasing tendency, however, after reaching the critical value of $30 \mathrm{~cm}$, it would decrease rapidly (shown in Fig. 18). As whole, aerobic bacteria is dominant in BAC bed.
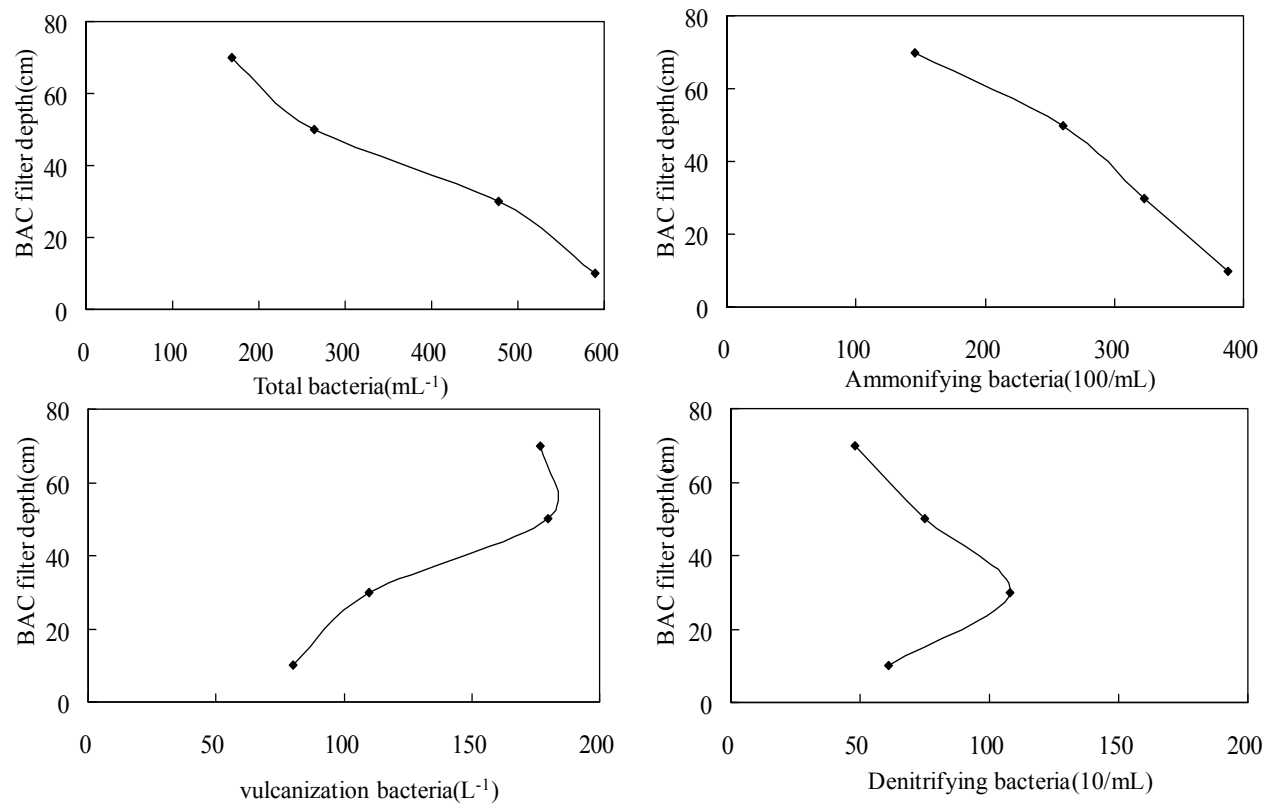

Figure 18. Distribution of biocommunity along BAC filter depth

As ammonifying bacteria is strictly aerobic, and denitrifying bacteria is amphitrophic, while anti-vulcanization bacteria is strictly anaerobic, the result shown in Fig. 18 is conducted by effects of two sides. Firstly, BAC is a kind of biofilm in essence, the thicker it gets, the more likely to create an anaerobic or hypoxia environment internal, which directly induces the existence of strictly anaerobic bacteria and amphitrophic bacteria. Secondly, variation of DO in activated carbon bed changes the distribution of biocommunity. Because aerobic bacteria is dominant in BAC bed, in the down-flow system, there is a decreasing tendency along the carbon layer (shown in Fig. 19), although, the concentration of DO in bottom of the layer is about $2-3 \mathrm{mg} / \mathrm{L}$, the flow inside BAC bed is laminar flow, which is not easy for the transmission of oxygen, hence, the bottom of activated bed shows anaerobic or anoxic characteristic, resulting in existence of amphitrophic bacteria and anaerobic bacteria. 


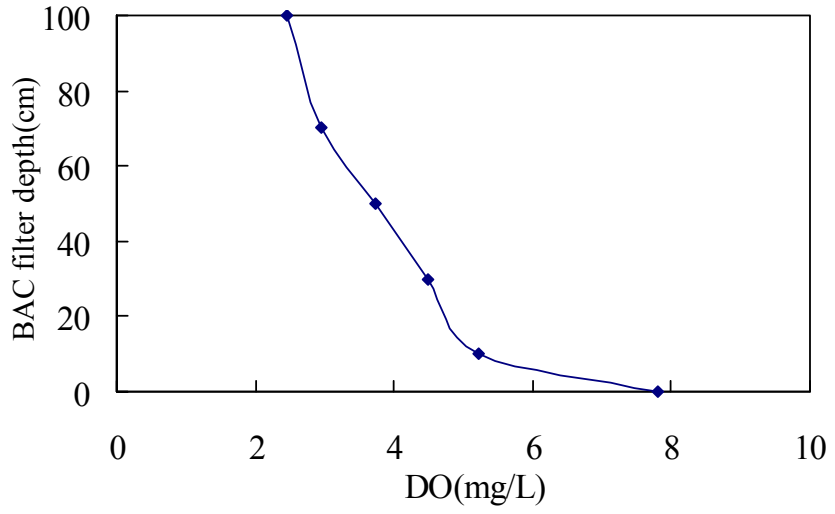

Figure 19. Variation of DO along BAC filter depth

During a steady operation of BAC process, a complex ecological system consists of bacteria, fungi, and algae which is from protozoa to metazoa is formed, which indicates the biofacies in BAC bed is of great abundance, and the ecological system of great diversity is fully developed which has a strong ability of avoiding the load impact. Part of the typical organisms inside BAC bed examined by microscope is shown in Fig. 20 ${ }^{[54]}$.

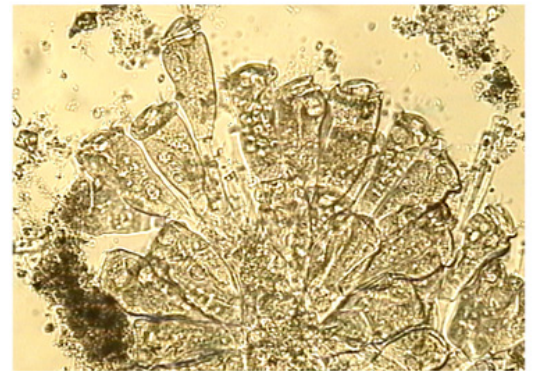

Epistylis

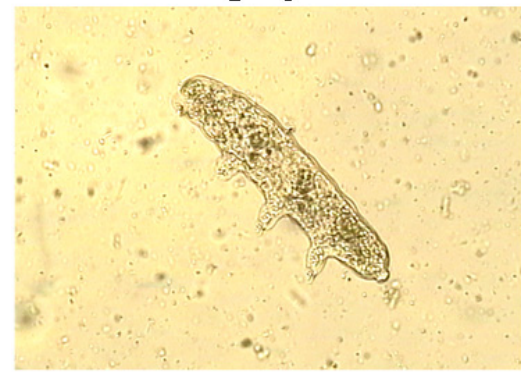

Water bear

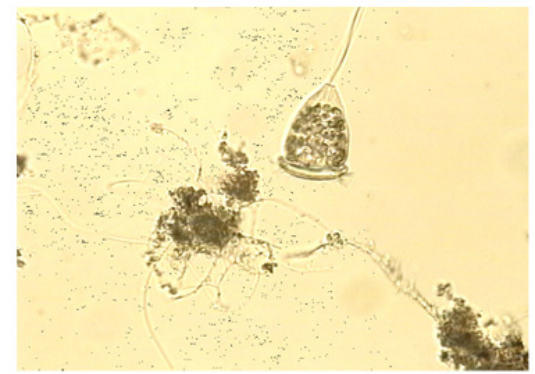

Vorticella

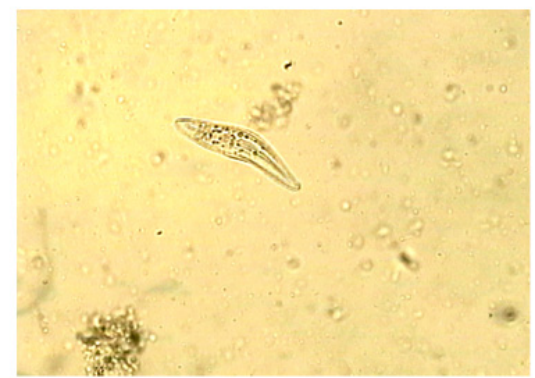

Litonotus

Figure 20. Microscope examination of microorganisms in BAC filter 


\subsubsection{Biocommunity diversity ${ }^{[55]}$}

By collecting the biofilm on the surface of BAC, taking the total DNA of microbe and building a cloning library of $16 \mathrm{~S}$ rDNA bacteria, as well as choosing a random one to clone with and conducting a DNA sequencing, the most similar bacteria to the cloned one can be determined after comparing with the community recorded in the database. Without relying on the domesticating method, the biocommunity's structure can be directly analyzed.

As shown in Table 4 , in the biocommunity, $\alpha$-Proteobacteria is dominant, $\beta$-Proteobacteria is the second category of this ecological system and $\delta$-Proteobacteria is the third. Meanwhile, Planctomycetes bacteria also take a big proportion in this gene library.

\begin{tabular}{c|c}
\hline Classification & Proportion $(\%)$ \\
\hline$\alpha$-Proteobacteria & 26.5 \\
$\beta$-Proteobacteria & 16.3 \\
$\gamma$-Proteobacteria & 2.0 \\
$\delta$-Proteobacteria & 16.3 \\
Nitrospira & 2.0 \\
Planctomycetes & 12.2 \\
Bacteroidetes & 2.0 \\
Gemmatimonadetes & 6.1 \\
Acidobacteria & 4.1 \\
Unclassified & - \\
Proteobacteria & - \\
Unclassified Bacteria & 10.2 \\
Actinobacteria & 2.0 \\
\hline
\end{tabular}

Table 4. Fraction of different bacteria in gene clone library

After entering the sequence of genotype into NCBI website and comparing it by BLAST procedure with the existing sequence, it can be concluded that many of the bacteria's $16 \mathrm{~S}$ rDNA sequencing has a rarely similarity with the existing ones in database, among which many have a similarity below 95\%, reaching $88 \%$ the minimum, and most of the sequencings are from environment like soil, activated sludge, underground water, rivers, lakes and the urban water supply system.

Proteobacteria and other phylogenetic trees (shown in Fig. 21 and Fig. 22) were built to further understand the status of bacterial system development and assure the species of the cloned bacteria. As shown in Fig. 21 and 22 in samples, most of the cloned ones are similar to the bacteria which are not cultivated, only cloned 1-22 shares the same species with Chitinimonas taiwanensis in the phulogenetic tree. 


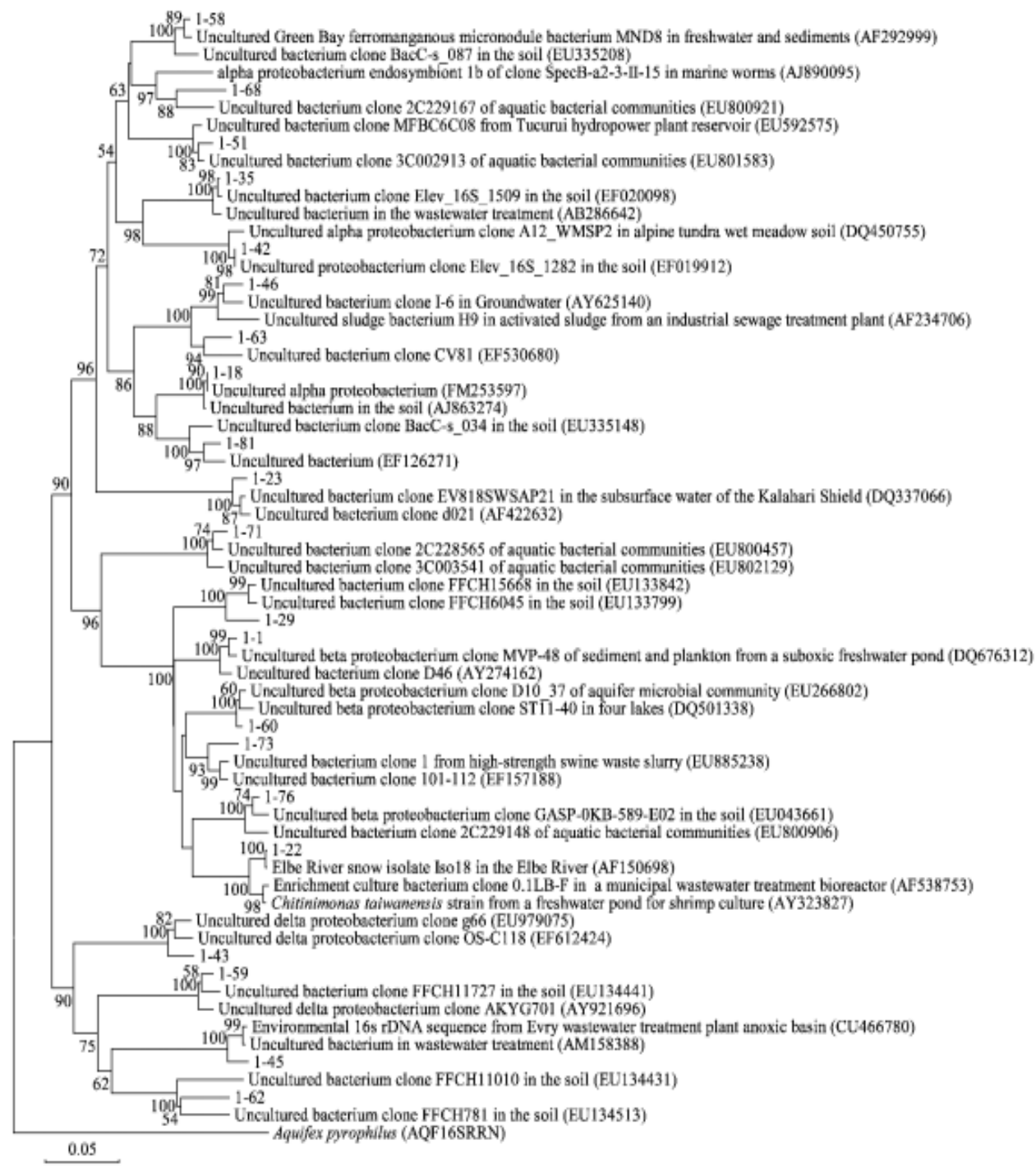

Figure 21. The Phulogenetic tree of Proteobacteria 


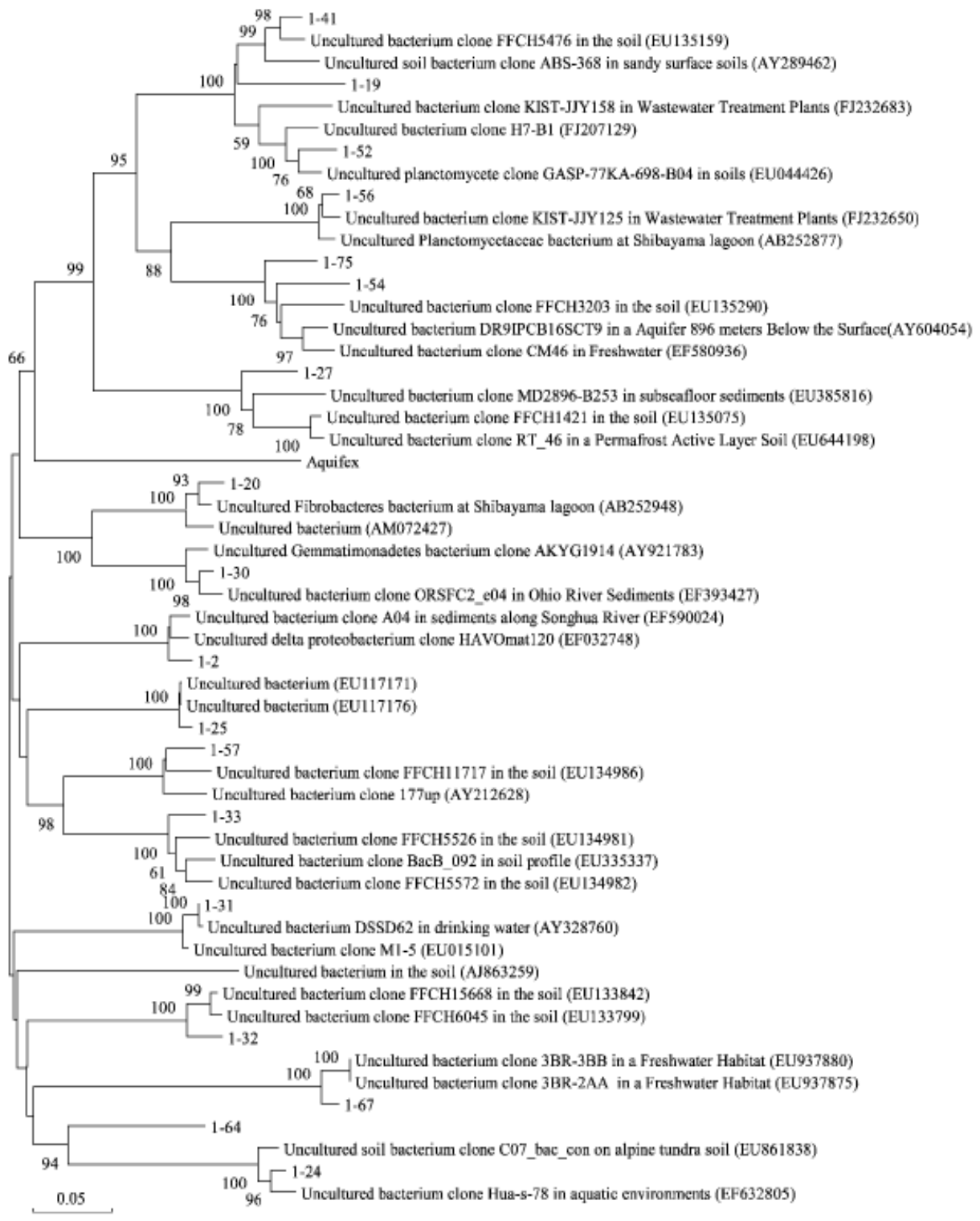

Figure 22. Phulogenetic trees of other bacterial system in carbon samples 


\subsection{Synergy of activated carbon adsorption and biodegradation}

\subsubsection{System construction and research method}

The adopted system device is shown in Fig. 23., ozone is dosed via titanium microporous aerator from the bottom column of contact reaction to realize the contact of gas and water in a reversal way. Generally the dosage of ozone is $1.5 \mathrm{mg} / \mathrm{mgTOC}$, and the retention time is 11 min. After ozonation, the outflow will equivalently enter the bio-ceramsite filter column (the diameter of ceramic particles is $2-3 \mathrm{~mm}$ ) and bio-activated carbon filter column through the high level cistern and the control valve respectively. Two filter columns are both made of organic glass with $70 \mathrm{~mm}$ inner diameter and $1650 \mathrm{~mm}$ height, and the effective height of each filer is $1050 \mathrm{~mm}$. For each column, there are sample outlets at height of $100 \mathrm{~mm}, 300 \mathrm{~mm}$, $500 \mathrm{~mm}$ and $700 \mathrm{~mm}$ along the top of each filter. The empty bed contact time for each column is $15 \mathrm{~min}$, and the cycle period of backwash is $3 \mathrm{~d}$. Under the same condition, by analyzing the removal effect of BAC and BCF towards DOC and BDOC to conduct quantitative analysis of organics removed by BAC adsorption and biodegradation, the theory on removal of pollutants in water by BAC will be discussed and the removal induced by the synergy effect of BAC adsorption and biodegradation ${ }^{[5,57]}$ will be determined accordingly in this part.

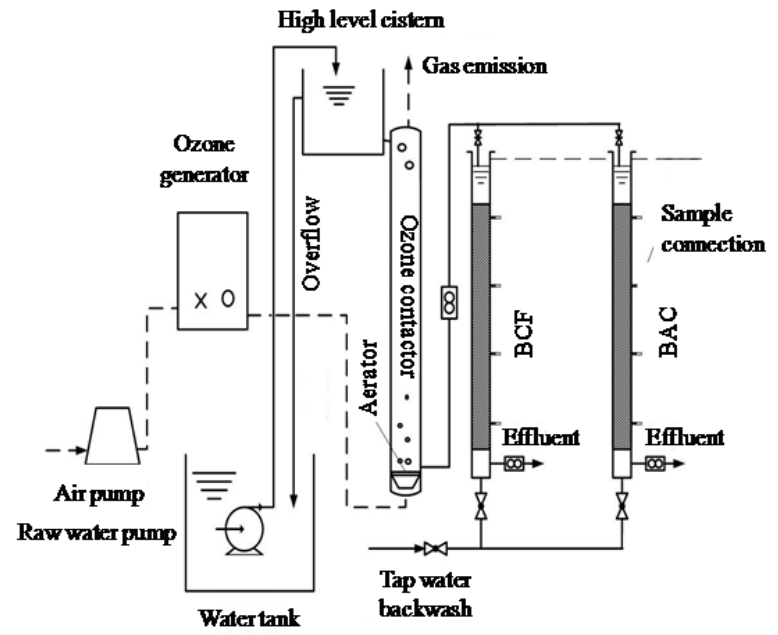

Figure 23. Pilot test arrangement

\subsubsection{Quantitative calculation method of relationship between adsorption and biodegradation in BAC filter bed}

\subsubsection{Quantitative calculation method}

This part compares $\mathrm{O}_{3}-\mathrm{GAC}$ with $\mathrm{O}_{3}-\mathrm{BCF}$ in which the biodegradation is dominant. By determining the iodide adsorption by $\mathrm{BCF}$, only to find out the iodide adsorption is nearly 
zero, which may conclude that for BCF filter bed the removal of organics in water is mainly realized by biodegradation, and the $\mathrm{BCF}$ adsorption is extremely faint. Assuming the quantity of biodegradation is in proportion to biological activity, the more active the microbe is, the more organics degraded will be. Therefore, determining the quantity of organics being degraded by BAC can be conducted by calculating the ratio of BAC biological activity with BCF biological activity, which can also determine the roles played by BAC filter bed adsorption and biodegradation in the process of organic removal. The calculation in details is shown in Fig. 24. Shown from the simplified calculation diagram in Fig. 24, two kinds of indexes need to be assessed to quantitatively determine the relationship between BAC adsorption and biodegradation within the process of organics removal:

1. to evaluate the comprehensive effect of BAC and BCF on organics removal, the system is characterized by DOC and BDOC;

2. to compare and analyze the biological activity of carriers from each filter bed.

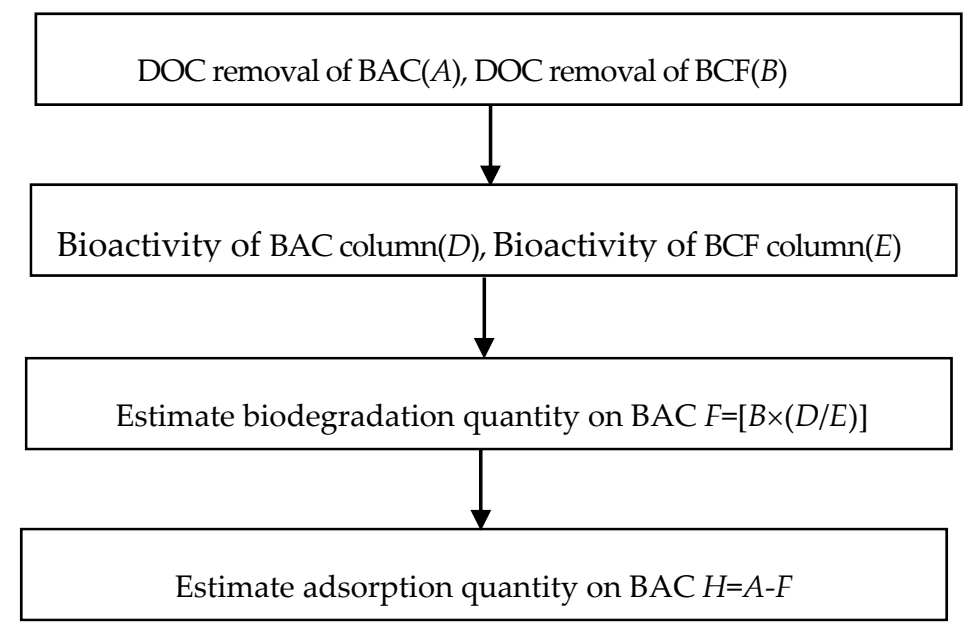

Figure 24. Illustration of quantification of the removal of organic matters by adsorption and biodegradation

\subsubsection{Analysis of biological activity}

The basic idea of in situ substrate uptake rate detection method ${ }^{[58,59]}$ is to converse timevariant variables into space-variant variables. First assumption is to consider matrix concentration as a differential function of filter bed height; the second assumption is that under proper conditions, any of the micro-unit taken from the inner-filter bed can achieve stability. Through the total differential method or the law of conservation of mass, the final expression of matrix degradation velocity can be determined, at this point, the law of conservation of mass is applied, for its intuitionism. 
As shown in Fig. 25, under a constant living environment for microbe, in situ oxygen uptake rate (ISOUR) can be described as the oxygen consumption of microbe grown on filter materials per unit time and volume (written as $R, \mathrm{mg} /(\mathrm{L} \cdot \mathrm{h})$ ). Consider the filter porosity in filter column as $e$, mass concentration of $\mathrm{DO}$ in inflow and outflow are $\rho\left(\mathrm{DO}_{\mathrm{i}}\right)$ and $\rho\left(\mathrm{DO}_{\mathrm{e}}\right)$ respectively, taking $\omega \mathrm{d} h$ as the micro-unit taken from depth of $h$ in bio-filter bed ( $\omega$ is section area of filer column, $\left.\mathrm{m}^{2}\right)$, and the variation in DO caused by the effect of microbe inside the micro-unit can be described as $R(1-e) \omega \mathrm{d} h$, according to the law of conservation of mass:

$$
\left(\rho\left(\mathrm{DO}_{\mathrm{i}}\right)-\rho\left(\mathrm{DO}_{\mathrm{e}}\right)\right) Q-R(1-e) \omega \mathrm{d} h=0
$$

ISOUR can be described as

$$
\frac{d C}{d t}
$$

In this equation: $\mathrm{Q}$ stands for the quantity of water through the filter column, $\mathrm{m}^{3} / \mathrm{h} ; v$ stands for the filter velocity, $\mathrm{m} / \mathrm{h}$;

$$
\frac{d \rho(D O)}{d h}
$$

stands for the gradient of DO at a height of $h$, along the filter variation height curve. As far as the aerobic biological treatment concerned, the biodegradation velocity on organic matrix is in proportion to its ISOUR. With abundant DO in BAC and BCF filter columns, the breeding microbe is mostly aerobic bacteria. Therefore, by calculating the oxygen consumption rate in the process of treating organics by BAC and BCF filter columns, the respective biological activity can be determined to analyze and evaluate the effect of biodegradation of BAC column.

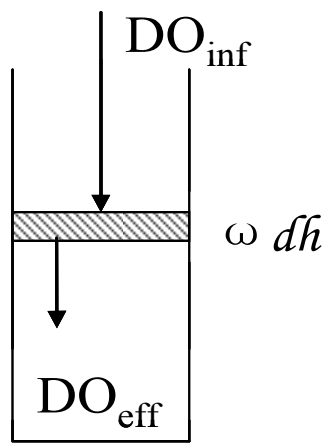

Figure 25. Calculation model of ISOUR 
3.3.3. Quantitative comparison between relationship of adsorption and degradation in BAC filter bed

\subsubsection{Analysis of biological activity (ISOUR)}

Variation of DO in each section of BAC and BCF is shown in Fig. 26, according to equation (3-2), the biological activity of each section can be determined, and the result is shown in Figure 27. As can be seen from Fig. 26 and 27, an obvious change in biological activity along with the various depth of carbon layer exists in both BAC filter bed and BCF filter bed, showing a gradual decreasing tendency along with the depth, which is closely related to the distribution of biomass on carriers. Biological activity ratio of BAC to BCF can be determined based on Fig. 27, shown as D/E in Fig. 24, and the result is shown in Fig. 28.

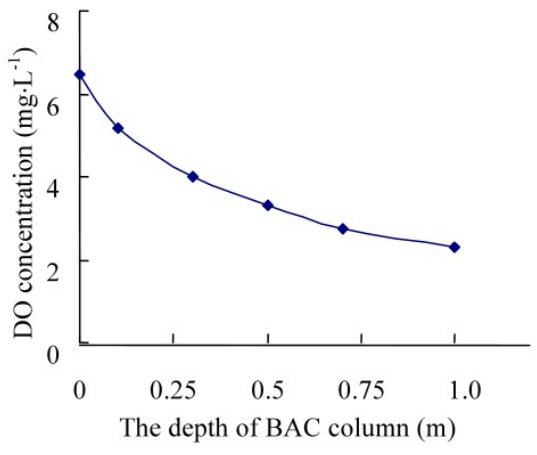

(a) $\mathrm{BAC}$

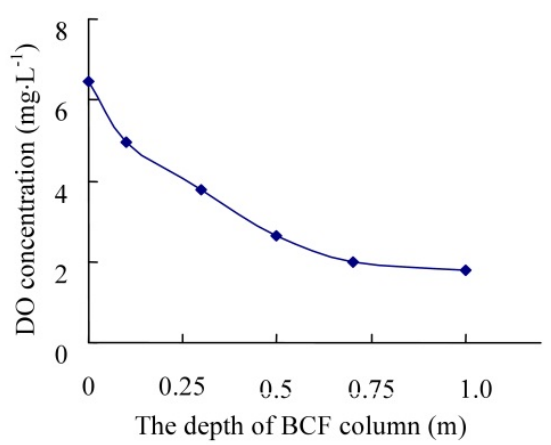

(b) $\mathrm{BCF}$

Figure 26. Variation of DO along $\mathrm{BAC}$ and $\mathrm{BCF}$ filter

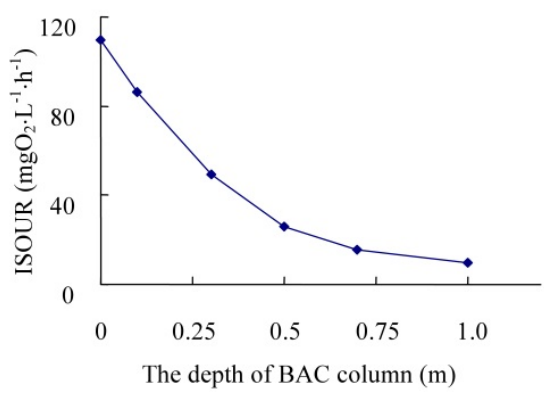

(a) BAC

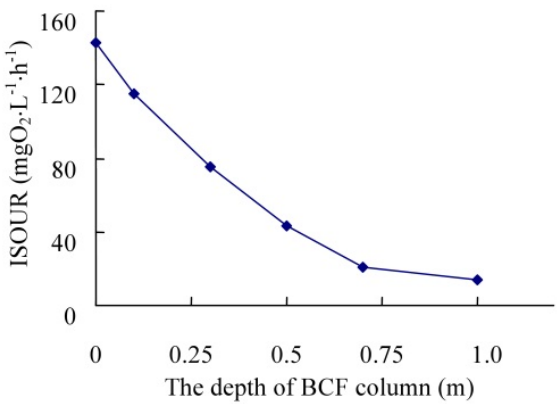

(b) $\mathrm{BCF}$

Figure 27. Variation of microbial activity along BAC and BCF filter 
Fig. 28 indicates that the microbial activity of BCF filter bed is higher than that of BAC bed, and $\mathrm{D} / \mathrm{E}$ for each section is ranging from 0.60 to 0.77 . Among those sections, four of them have a ratio higher than 0.7 , hence $\mathrm{D} / \mathrm{E}=0.72$ is set in quantitative calculation.

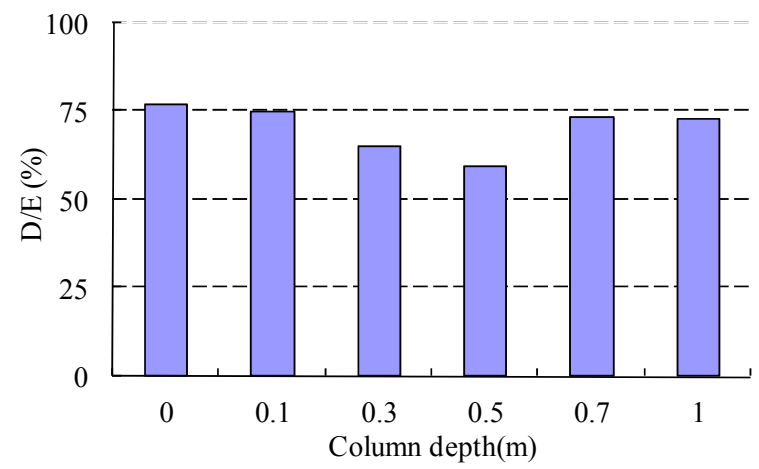

Figure 28. Ratio of microbial activity in BAC and BCF section (D/E)

\subsubsection{Analysis of the organic removal effect of $B A C$ and $B C F$}

The respective removal effect of BAC filter bed and BCF filter bed on DOC and BDOC after ozonation is shown respectively in Fig. 29 and Fig. 30. Only a few DOC, which accounts for $4 \%$ of raw water is removed by ozonation. For calculation, the removal of DOC and BDOC shown in Fig. 29 and Fig. 30 is in relative terms with ozonation. Analysis of the statistics of Fig. 29 and Fig. 30 is shown in Table 5, in which NBDOC stands for nonbiodegradable dissolved organic carbon. As shown in Table 5, the removal effect of BAC on DOC is mainly focused on removing BDOC, among which removal of BDOC accounts for $85 \%$ of the degradation DOC, while for BCF filter bed, this proportion can be as high as $98 \%$.

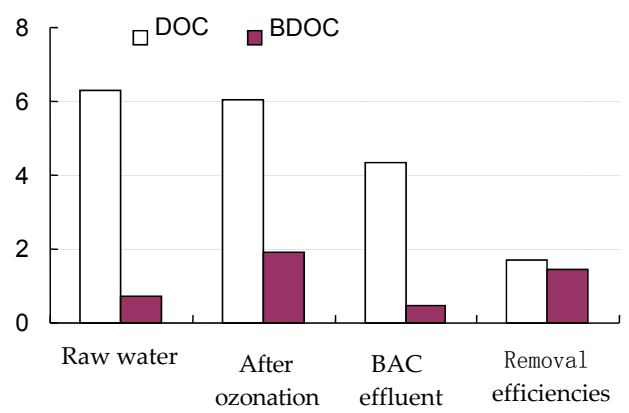

Figure 29. Results of DOC and BDOC removal in BAC filter 


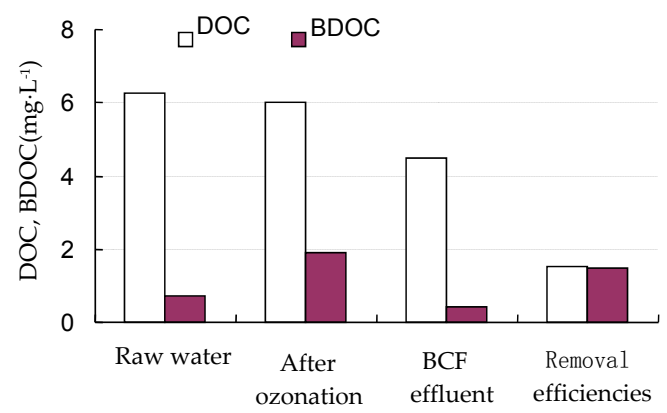

Figure 30. Results of DOC and BDOC removal in BCF filter

\begin{tabular}{ccccc}
\hline \multirow{2}{*}{ Column } & \multirow{2}{*}{ DOC removal } & \multicolumn{2}{c}{ BDOC removal } & \multirow{2}{*}{ BDOC/DOC (\%) } \\
\cline { 3 - 4 } & & NBDOC & BDOC & \\
\hline BAC & 1.685 & 0.234 & 1.451 & 85 \\
BCF & 1.525 & 0.03 & 1.495 & 98 \\
\hline
\end{tabular}

Table 5. Calculation results of DOC and BDOC removal in BAC and BCF filter

\subsubsection{Quantitative analysis of $\mathrm{O}_{3}-\mathrm{BAC}$ adsorption and biodegradation}

According to the calculation method in Fig. 24, and considering the analysis of BAC, BCF biological activity and their effects on removing organics, Table 6 shows quantitative calculation results of organic matter removal by adsorption and biodegradation in BAC filter. To intuitively understand how $\mathrm{O}_{3}$-BAC biodegradation and adsorption work, Fig. 31 along with the analysis of Table 6 and Fig. 29, shows a simplified model of O3-BAC removes organics.

\begin{tabular}{cccc}
\hline \multirow{2}{*}{ Column } & \multirow{2}{*}{ DOC removal } & \multicolumn{2}{c}{ BDOC removal } \\
\cline { 3 - 4 } & & NBDOC & BDOC \\
\hline Adsorption & 0.595 & 0.234 & 0.361 \\
Biodegradation & 1.09 & 0 & 1.09 \\
Total & 1.685 & 0.234 & 1.451 \\
\hline
\end{tabular}

Table 6. Calculation results of organic matter removal by adsorption and biodegradation in BAC filter

As shown in Fig. 31, it is conducted by the synergy effect of activated carbon adsorption and biodegradation of $\mathrm{O}_{3}$-BAC. Under the system research conditions, BAC bed biodegradation is dominant which accounts for $65 \%$ removal of total organics, furthermore, this $65 \%$ is mainly organics of BDOC, which indicates that the main organics removed by biodegradation is readily degradable dissolved organics, which can be concluded that biodegradation has a remarkable selectivity. In contrast, activated carbon adsorption plays a supporting role in the system, while via adsorption the quantity of removed difficult biodegradable material is roughly similar to the quantity of the readily one ${ }^{[60]}$. 


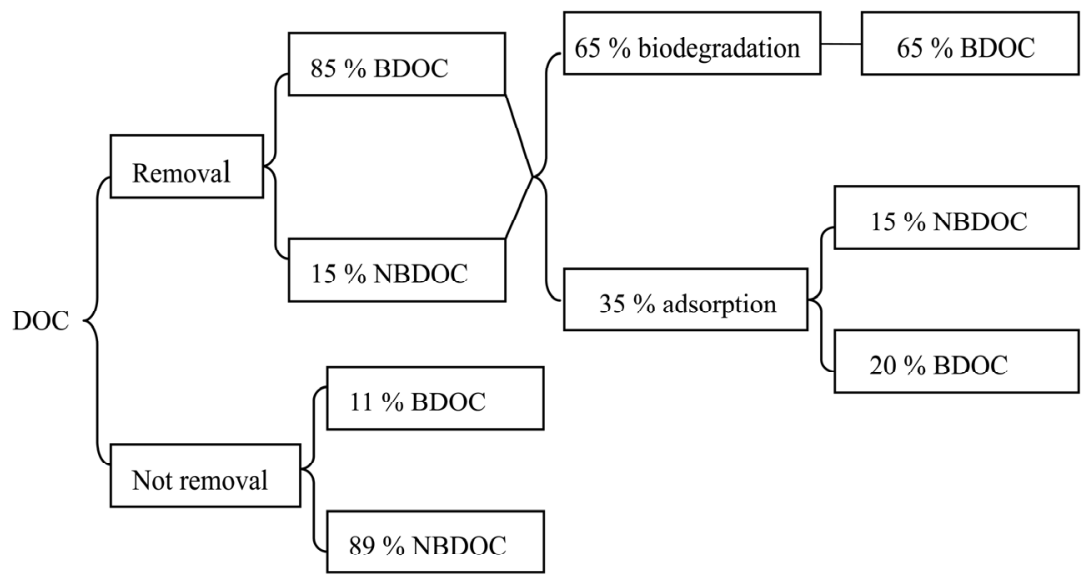

Figure 31. Illustration of organic matter removal by BAC filter after ozonation

\subsection{Degradation kinetics of pollutants in BAC bed}

\subsubsection{Kinetics model establishment}

Adopted system device is shown in Fig. 32. The relationship among microbial growth, the initial concentration of microbe and that of the substrate is the key factor to establish the degradation kinetics model. The relationship can be reflected by various models and the Monod equation is universally acknowledged as the practical model[61]. For water treatment field, the specific degradation velocity of the substrate is more practical than the specific growth velocity of microbe. Considering the specific degradation velocity of the substrate according to the physical law, the equation below is founded ${ }^{[62]}$ :

$$
-\frac{d C}{d t}=v_{\max } \frac{X C}{K_{s}+C}
$$

Wherein, $\frac{d C}{d t}$ stands for the degradation velocity of organic substrate; $C$ stands for residual organic substrate concentration in mixed liquor after a reaction time $t ; K_{s}$ stands for saturated constant; $v_{\max }$ stands for the max specific degradation velocity of organic substrate.

In the equation, $\mathrm{C}$ is the key factor for calculating kinetic equation. When $K_{s}>C$, the equation below is founded:

$$
-\frac{d c}{d t}=k_{1} X C
$$

When $K_{s}<\mathrm{C}$, the equation below is founded:

$$
-\frac{d c}{d t}=k_{2} X
$$




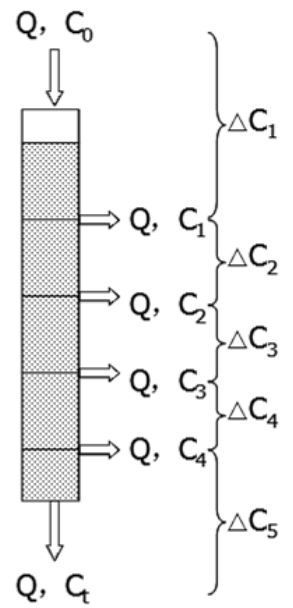

Figure 32. Illustration of material balance

Taken $X$ (biomass) as horizontal coordinate and $\frac{d C}{d t}$ as vertical coordinate, if the diagram obtained is linear, the model belongs to high matrix organic degradation, while if the diagram is in exponential form, the model belongs to low matrix organic degradation.

As both BAC and BCF have a homologous microbial characteristic, by drawing an analogy with the degradation model of $\mathrm{BCF}$, the BAC biodegradation effect can be described. According to the experimental system, material balance can be established which is shown in Fig. 32.

As shown in Fig.32, according to material balance law, along the section, the equation below is founded:

$$
Q C_{0}=Q\left(C_{1}+\sum_{i=1}^{1} \Delta C_{i}\right)=Q\left(C_{2}+\sum_{i=1}^{2} \Delta C_{i}\right)=Q\left(C_{3}+\sum_{i=1}^{3} \Delta C_{i}\right)=Q\left(C_{4}+\sum_{i=1}^{4} \Delta C_{i}\right)
$$

In which $\Delta C$ can be calculated by each $C$ of all the sections, $\Delta t$ can be calculated by the height of filter through each section and the filter velocity; the biomass of each BCF section represented by $\mathrm{X}$ can be measured, hence, taking biomass as the horizontal coordinate, $\Delta \mathrm{Ci} / \Delta \mathrm{t}$ of each section as the vertical coordinate to conduct linear regression analysis so as to determine the type of biodegradation model.

\subsubsection{Characteristic of $B A C$ degradation towards organics}

\subsubsection{Characteristics of BCF bed degradation}

Fig. 33 shows the monitoring result of biomass in different BCF bed sections during a 7month operation period. It can be seen from Fig. 33 that less biomass initially, till $20^{\text {th }}$ May, the biomass of each section increased obviously and being steady gradually, which 
symbolically means it is mature for biofilm colonization in bio-ceramsite filter bed. However, from the middle of October, biomass of each section is decreasing rapidly, which is partially induced by the gradual reduction for water temperature during operational period. Therefore, it is appropriate for choosing the data recorded from $20^{\text {th }}$ May to the middle of October to be compared with. Fig. 34 shows the BDOC variation of each BCF bed section in this period. Fig. 34 suggests that organic concentration of each section is relatively steady and decreases along the direction of water flow, as well as gradual reduction between the differences of organic concentration from each section.

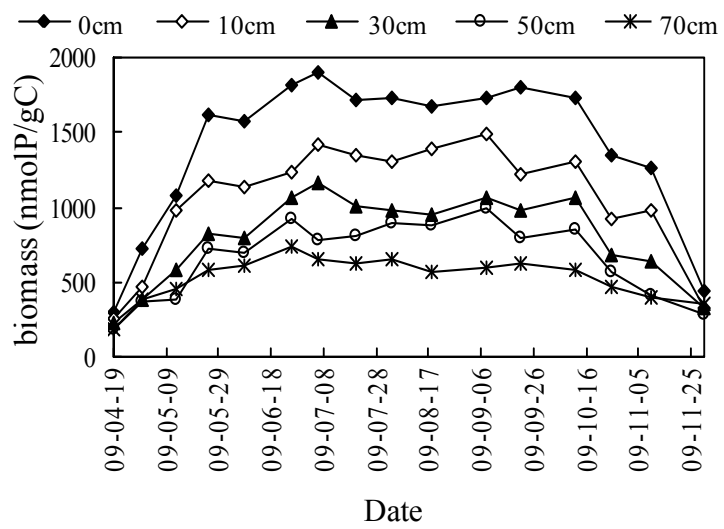

Figure 33. Variation of biomass along BCF bed

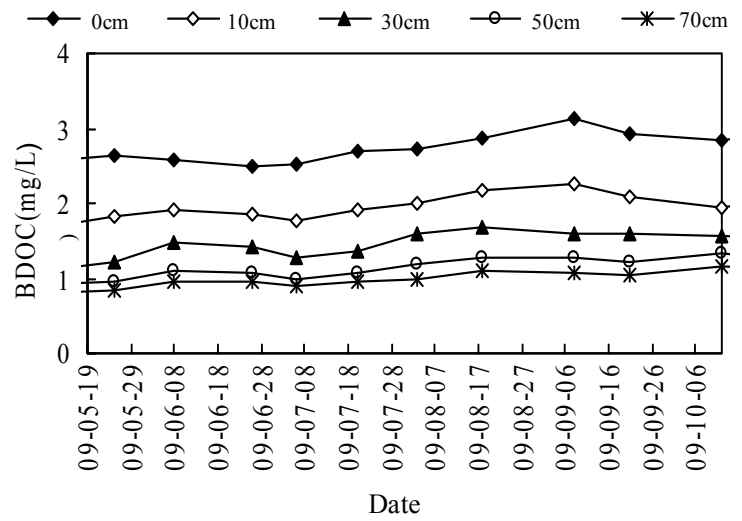

Figure 34. Variation of BDOC along BCF bed

By choosing the biomass of each section in the duration from $20^{\text {th }}$ May to the middle of October and the mean value of BDOC variations to analyze the relationship between the biomass and $\Delta C i / \Delta t$ variation according to the built model, the result is shown in Fig. 35 . From Fig. 35, BCF bed biodegradation is in compliance with high matrix featured degradation model. 


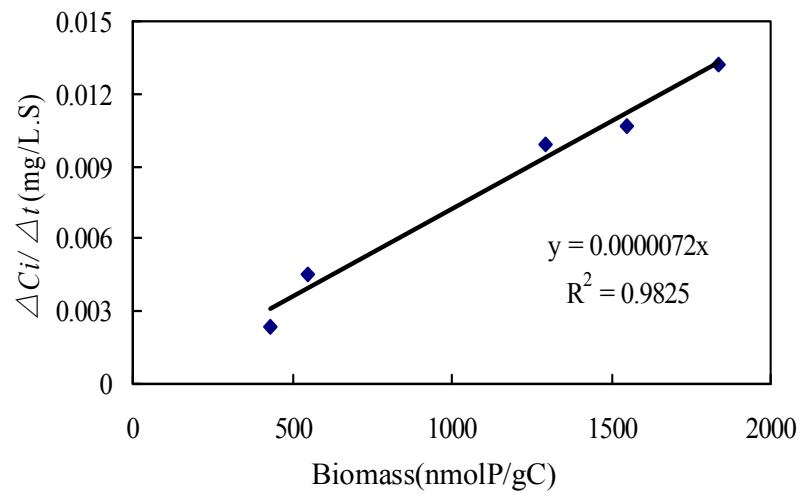

Figure 35. Calculation of BDOC degradation model in BCF column

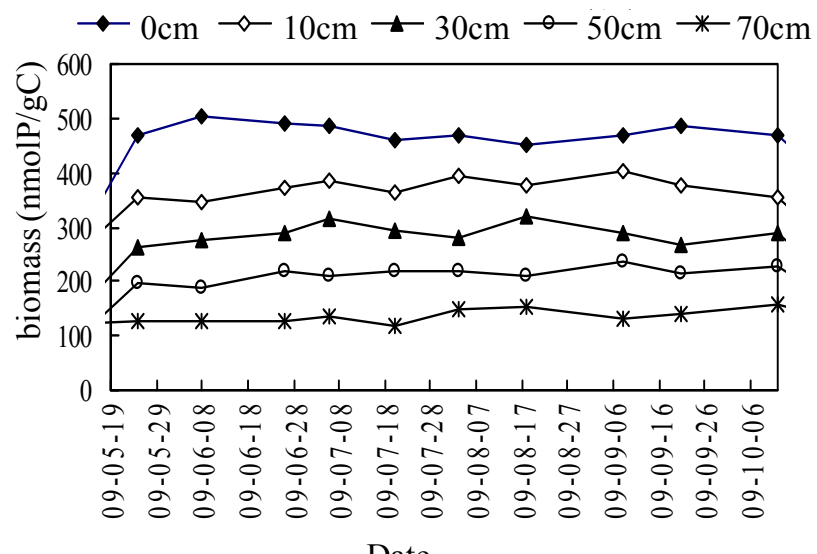

Date

Figure 36. Variation of biomass along BAC column

\subsubsection{Characteristic of $B A C$ bed degradation}

The variation of biomass in BAC bed at the same period is shown in Fig. 36. Fig. 36 shows that the biomass of $\mathrm{BCF}$ is much more than that of BAC, considering from the calculation above, we can find that for BCF system, biodegradation is in compliance with high matrix kind. Hence, it is the same with BAC system. Considering the two matrixes share the same homologous microbial, we can establish the BAC biodegradation equation by employing the calculated K:

$$
\Delta C_{i} / \Delta t=0.0000072 X_{i}
$$

Wherein $\Delta C_{i}$ stands for the difference between the organic substrate concentration in mixed liquor residual of section $i$ and that of section $i-1 ; \Delta_{t}$ stands for hydraulic retention time from section $i$ to section $i-1 ; X_{i}$ stands for biomass of section $i$. 


\subsubsection{Analysis of $B A C$ bed organics degradation}

Fig. 37 shows the analysis of the monitored variation of organics in each section of BAC bed at the same period, from which, organics concentration along the direction of water flow is decreasing gradually. However, as discussed previously, variation of organics is not only conducted by biodegradation, among which activated carbon adsorption is of the same importance. According to the biodegradation model mentioned previously, via calculation, BDOC removal conducted by microorganism biodegradation of each section as well as organics quantity adsorbed by activated carbon can be defined as $\triangle$ BDOC.

It can be seen from Fig. 37 that as the carbon layer goes deeper, the biomass become less gradually, also a decreasing in biodegradation and the BDOC quantity which is degraded by microbe, while at this point, the adsorption increases gradually.

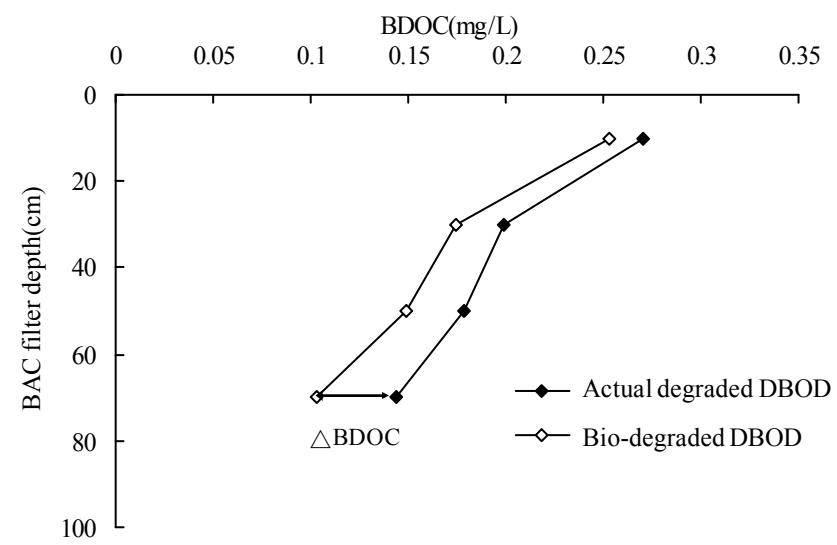

Figure 37. Calculation results of organic matter removal by degradation in BAC bed

\section{Study on the safety of water quality by $\mathrm{O}_{3}-\mathrm{BAC}$ process}

\subsection{Safety of microorganism}

Because of ecclasis of microorganism and hydraulic erosion, microorganism may release from activated carbon bed, which will cause a series of water quality safety problems. Therefore, the microorganism safety of $\mathrm{O}_{3}-\mathrm{BAC}$ process is very important for its application.

Microorganism safety of $\mathrm{O}_{3}-\mathrm{BAC}$ technology should include the following four aspects[63], which characterize microorganism safety from different aspects respectively. Firstly, pathogenic microorganisms and toxic substances produced by their metabolism are the core problems concerning biological safety. Secondly, biocommunity mainly including bacteria, protozoa and metazoan is the expansion of the first aspect, which is based on some kinds of correlativity relationships between the biocommunity and pathogenic microorganisms. Thirdly, there is a certain connection between water quality parameters such as turbidity, 
biological particle number and the risk of pathogenic microorganisms. Fourthly, Assimilable Organic Carbon (AOC) is one of the indexes characterizing bacteria regrowth potential. Low AOC indicates a small possibility for bacteria regrowth and low pathogenic microorganisms risk $^{[64]}$.

Correlations exist among those four aspects. Among them, the first and second aspects are relatively intuitive, and have intimate connections with microorganism safety, but not easy to be detected. The third and the fourth aspects are indirect indexes that can be detected quickly and easy to be automatically controlled, which is particularly important to the operation management of water plant.

According to the research and operation practice, $\mathrm{O}_{3}-\mathrm{BAC}$ process produced abundant biocommunity, but pathogenic microorganisms were not found in the activated carbon and so were significant pathogenic microorganisms in effluent as well[64]. The effluent turbidity maintained under 0.1NTU on the whole, but it may beyond the standard during the preliminary stage $(0.5 \sim 1 \mathrm{~h})$, the later period or the whole procedure of activated carbon bed filtration. Particle number was generally less than $50 / \mathrm{ml}$ in outflow, when the system worked stably, thus the microorganism safety can be guaranteed. However, it would reach up to 6000 per milliliter in primary filtration water. On the other hand, the effluent AOC basically maintained under $100 \mu \mathrm{g} / \mathrm{L}$. According to relevant research result, AOC concentration in $50 \sim 100 \mu \mathrm{g} / \mathrm{L}$ could restrain the growth of colibacillus.

On the whole, microorganism safety problems have not been found in $\mathrm{O}_{3}-\mathrm{BAC}$ process until now, while it must arise enough attention. This problem should be controlled by optimizing design parameters, strengthening the operation management and developing new treatment technology.

Ozonation contact reactor should be set up with more ozone dosing points to guarantee the removal effect of cryptosporidium and giardia insect, and CT value should be greater than 4 generally. The thickness of the activated carbon bed should be greater than or equal to $1.2 \mathrm{~m}$ in general. In order to guarantee microorganism safety, a sand layer with certain thickness shall be considered to be added under the carbon layer. Besides, setting up reasonable operation period for biological activated bed and strengthening the management of initial filtrated water. If possible, water quality monitoring of every single biological activated carbon processing unit should be taken into account, for example, setting online monitoring equipments for turbidity and grain number. Furthermore, it can be effective by using other processing technologies or combining $\mathrm{O}_{3}-\mathrm{BAC}$ with other technologies to solve this problem. For instance, reversed $\mathrm{O}_{3}-\mathrm{BAC}$ and sand filter or O3-BAC and membrane filtration hybrid process (UF and MF) can be applied[65].

\subsection{Safety of water quality}

In addition to microorganism safety, toxic and hazardous compounds may be produced in actual operation of $\mathrm{O}_{3}$-BAC process. Those toxic and hazardous compounds can be divided into two parts in general, namely ozonation byproducts and biodegradable byproducts respectively. 


\subsubsection{Ozonation byproducts}

Ozonation byproducts can be divided into two kinds according to its origin, which are produced under the condition of humic substances and bromide existing in water. The former is caused by the reaction of $\mathrm{O}_{3}$ and hydroxyl radicals, and the latter is caused by hypobromous acid. Composition of byproducts would become more complicated when ammonia nitrogen and amino acid exist at the same time ${ }^{[66]}$.

\subsubsection{Byproducts caused by humic substances}

$\mathrm{HA}$ is the main composition of NOM in water, the molecular weight of material after ozonation is lower than that of NOM, and contains more oxygen during the reaction. The main byproducts are shown in Table 7. Among these byproducts, carbonyl compounds especially aldehydes should be paid most attention. Animal experiments indicated that formaldehyde, acetaldehyde, glyoxal and methylglyoxal have acute toxicity as well as and chronic toxicity, and furthermore, tube test also implied that these substances have genotoxicity, carcinogenicity, mutagenicity in different levels.

\begin{tabular}{|c|c|c|c|}
\hline \multirow{4}{*}{$\begin{array}{l}\text { Carbonyl } \\
\text { compound }\end{array}$} & \multirow{2}{*}{ Aldehydes } & Aliphatics & Formaldehyde、Acetaldehyde、Propionaldehyde \\
\hline & & Aromatic & Benzaldehyde \\
\hline & Dialdehyde & Aliphatics & $\begin{array}{c}\text { Glyoxal 、 Methylglyoxal 、Maleic aldehyde 、 } \\
\text { Furaldehyde }\end{array}$ \\
\hline & \multicolumn{2}{|c|}{ Ketones } & Acetone \\
\hline \multicolumn{3}{|c|}{ Oxygenous carboxylic acid } & $\begin{array}{l}\text { Aldehydoformic acid、Methylglyoxal、Diethyl } \\
\text { Ketomalonate、 }\end{array}$ \\
\hline \multirow{3}{*}{$\begin{array}{c}\text { Carboxylic } \\
\text { acid }\end{array}$} & \multicolumn{2}{|c|}{ Monocarboxylic acid } & Formic acid、 Acetic acid $\sim \mathrm{C}_{29} \mathrm{H}_{59} \mathrm{COOH}$ \\
\hline & \multicolumn{2}{|c|}{ Dicarboxylic acid } & $\begin{array}{c}\text { Oxalic acid、 Maleic acid、Galactaric acid、 } \\
\text { Fumaric acid }\end{array}$ \\
\hline & \multicolumn{2}{|c|}{ Acromatic carboxylic acid } & Benzoic acid、Phthalic acid \\
\hline \multicolumn{3}{|c|}{ Bioxide } & Hydroquinone、Catechol \\
\hline \multicolumn{3}{|c|}{ Other } & Heptane、Octane、Toluene \\
\hline
\end{tabular}

Table 7. Main ozone byproducts owing to NOM

\subsubsection{Byproducts caused by bromine}

When bromine exists in water, bromine will be oxidized into hypobromous acid by ozone, and then hypobromous acid will be oxidized into bromate, which has carcinogenicity to human body[6]. When ammonia nitrogen and amino acid exist at the same time in water, the reaction speed of bromate and ammonia nitrogen is faster, thus, dosing little amounts of ammonia would often restrain the production of organobromine compounds. Moreover, when bromine concentration is higher in the water, cyanogen bromide becomes the main ozonation byproduct ${ }^{[68]}$. Byproducts caused by bromide are shown in Table 8 . 


\begin{tabular}{|c|c|c|}
\hline \multirow{6}{*}{$\begin{array}{l}\text { By-products caused } \\
\text { by bromides }\end{array}$} & Bromoform & $\mathrm{CHBr}_{3}$ \\
\hline & Bromoacetic acid & $\begin{array}{c}\text { Bromacetic acid } \\
\text { Dibromoaceticacid } \\
\text { Tribromoacetic acid }\end{array}$ \\
\hline & Bromohydrin & Bromine sec-butanol \\
\hline & Acetonyl bromide & $\begin{array}{l}\text { Bromopropanone } \\
\text { Dibromoacetone }\end{array}$ \\
\hline & $\begin{array}{l}\text { Hypobromous acid } \\
\text { Hypobromite }\end{array}$ & $\mathrm{HBrO} 、 \mathrm{MeBrO}$ \\
\hline & Bromic acid、Bromate & $\mathrm{HBrO}_{3} 、 \mathrm{MeBrO}_{3}$ \\
\hline \multirow{4}{*}{$\begin{array}{l}\text { By-products under } \\
\text { the condition of } \\
\text { ammonia nitrogen } \\
\text { coexist }\end{array}$} & Bromopicrin & $\mathrm{CBr}_{3} \mathrm{NO}_{2}$ \\
\hline & Dibromoacetonitril & $\mathrm{CHBr}_{2} \mathrm{CN}$ \\
\hline & Cyanogen bromide & $\mathrm{BrCN}$ \\
\hline & Bromine amine & $\mathrm{NH}_{2} \mathrm{Br} 、 \mathrm{NHBr}_{2} 、 \mathrm{NBr}$ \\
\hline
\end{tabular}

Table 8. Main ozone by-products owing to $\mathrm{Br}^{-}$

Ozonation byproducts could be removed by adsorption of activated carbon. Meanwhile, ozonation and hypermanganate hybrid method will reduce the amount of byproducts. Taking more ozone dosing points can shorten the mean contact time and reduce the residual ozone concentration, thus bromate production will be decreased accordingly. Moreover, dosing acid to lower $\mathrm{pH}$, ammonia, excessive $\mathrm{H}_{2} \mathrm{O}_{2}$ and $\mathrm{OH}$ scavenger to water may reduce $\mathrm{BrO}_{3}{ }^{-}$production ${ }^{[69]}$ as well.

\subsubsection{Bio-degradation byproducts}

The microorganisms in the BAC will produce some microbial products such as SMP (soluble microbial products), EPS (extracellular polymeric substances), etc., when microorganisms degrade organics in wastewater.

Most of such substances are difficult to be degraded and hazardous to human. When drinking water is treated by $\mathrm{O}_{3}-\mathrm{BAC}$ advanced treatment process, the degradation byproducts in a certain concentration will be produced, which causes health risks by drinking water. The disinfection byproducts will be formed through difficult biodegradation byproducts during chlorination, which are complex, various and more harmful to human body. The microbial degradation byproducts are organic, thus these substances may lead to the growth of bacteria in the pipeline. Moreover, the microbial degradation products will result in membrane clogging, and reduce the membrane flux as well as the membrane life during the $\mathrm{O}_{3}-\mathrm{BAC}$ and membrane filtration hybrid process to produce high-quality water ${ }^{[10]}$.

Although the effluent of BAC may contain some microbial byproducts, the content is limited and is not harmful for human health. Therefore, controlling the ozonation byproducts is more important and meaningful. 


\section{Author details}

Pengkang Jin, Xin Jin, Xianbao Wang, Yongning Feng and Xiaochang C. Wang School of Environment $\mathcal{E}$ Municipal Engineering, Xi'an University of Architecture E Technology, Xi'an, P. R. China

\section{References}

[1] He Wenjie, Li Weiguang, Zhang Xiaojian, Huang Tingling, Han Hongda. Novel Technology for Drinking Water Safety [M]. China Architecture \& Building Press. 2006

[2] Weissenhorn FJ. The Behavior of Ozone in the System and Its Transformation [J]. AMKBerlin, 1977, (2): 51-57.

[3] Parkhurst, J. P. et al. Pomona Activated Carbon Pilot Plant [J]. J. WPCF, 1976, 37 (1).

[4] Li Weiguang, Ma Fang, Yang Xianji, Zhao Qingliang, Wang Qingguo. A Study on Purification Performance of Biological Activated Carbon [J]. Journal of Harbin University of Civil Engineering and Architecture, 1999, (32) 6: 105-109. (In Chinese)

[5] Eberhardt M S. Untersuchunger Zur Berwendung Biolosisch Arbeitender Ativkohle Gilter Bei Der Trinkwasseranf Bereitung[J].Wasser-Abwasser, 1975, 116(6): 29-34.

[6] Sontheimer H. The Mulheim Process. J. AWWA, 1978, 70(7): 62-68.

[7] Greening F. Experience with Ozone Treatment of Water in Switzerland. In: Andrews G F, eds. Proceedings $8^{\text {th }}$ Ozone World Congress. Zurich: IOA, 1987, 49-54.

[8] Gomella C. Ozone Practices in France. J. AWWA, 1972, 64(1): 41-45.

[9] Tian Yu, Zeng Xiangrong, Zhou Ding. Development of Coordinating Technology for Ozonation and Biological Activated Carbon System [J]. Journal Of Harbin Institute Of Technology, 1998, 30 (2): 21-25. (In Chinese)

[10] Gao Naiyun, Yan Min, Le Yuesheng. Strengthening Treatment Technology for Drinking Water [M]. 2005.(In Chinese)

[11] Qing Tian, Jihua Chen. Application of bioactivated carbon (BAC) Process in Water and Wastewater Treatment [J]. Environmental Engineering. 2006, 24 (1): (84-86). (In Chinese)

[12] Shucheng Lan. Biological Activated Carbon Technology and Its Application for Wastewater Treatment [J]. Water \& Waste Water Engineering. 2002, 28 (12): 125. (In Chinese)

[13] Xiaochang Wang. Theoretical and Technical Aspects of Ozonation in Drinking Water Treatment [J]. J. Xi'an Univ. of Arch. \& Tech. 1998, 30 (4): 307-311. (In Chinese)

[14] Liang Xu, Wenmei Jiang, Yu Zhang, Jinguan Liu. Progress Research and Application of Biological Activated Carbon Technology in Water Treatment [J]. Research progress. 2010, 30 (5): 32-34. (In Chinese)

[15] Alexander S., Sirotkin, Larisa Yu., Koshkina, Konstantin G, Ippolitov. The BAC-Process for Treatment of Wastewater Containing Non, Ionogenic Synthetic Surfactants [J]. Wat. Res., 2001, 35(13): 3265-3271.

[16] Baoan Zhang, Hongwei Zhang, Xuehua Zhang, Liankai Zhang. Development of the Application of Biological Activated Carbon to Water Treatment [J]. Industrial Water Treatment. 2008, 28(7): 6-8. (In Chinese) 
[17] Walker G M, Weateherley L R. Biological Activated Carbon Treatment of Industrial Wastewater in Stirred Tank Reactors [J]. Chemical Engineering Journal, 1999, 75(3):201206.

[18] Wenjie He, Weiguang Li, Xiaojian Zhang, Tingling Huang, Hongda Han. Novel Technology for Drinking Water Safety [M]. China Architecture \& Building press. 2006.

[19] B.Z Wang. The Efficacy and Mechanism of Removal of Organic Substances from Water by Ozone and Activated Carbon. Water Science and Technology 1999, 30(1): 43-47.

[20] Y Wang, J.Hi Qu, R.C Wu, et al. The Electrocatalytic Reduction of Nitrate in Water on Pd/Sn-modified Activated Carbon Fiber Electrode. Water Research. 2006(40): 1224-1232.

[21] P. Wentworth, J. Nieva, T C.akeuchi, et al. Evidence for Ozone Formation in Human Atherosclerotic Arteries. Science. 2003, 302(7): 1053-1056.

[22] Woo Hang Kim, Wataru Nishijima. Micropollutant Removal with Saturated Biological Activated Carbon (BAC) in Ozonation-BAC Process. Water Science and Technology. 1997, 36(12): 283-298.

[23] W. Nishijima, E.G Speitel. Fate of Biodegradable Dissolved Organic Carbon Produced by Ozonation on Biological Activated Carbon. Chemosphere. 2004, 56(2):113-119.

[24] X. Zhao, R.F Hickey, T.C Voice. Long-term Evaluation of Adsorption Capacity in Biological Activated Carbon Fluidized Bed Reactor System. Water Research. 1999, 33(13): 2983-2991.

[25] Anneli Andersson, Patrick Laureent. Impact of Temperature on Nitrification in Biological Activated Carbon (BAC) Filters Used for Drinking Water Treatment. Water Research. 2001, 35(12): 2923-2934.

[26] Xiaorong Wang, Guangping Hao, Wencui Li. Research and application of biological activated carbon for water treatment. Chemical industry and engineering process. 2010, 29(5): 932-937. (In Chinese)

[27] Pengkang Jin, Xu Wang, Jianjun $\mathrm{Xu}$, Xiaochang Wang. Analysis on the process of biological activated carbon bed with the effect of ozonation. Technology of water treatment. 2010, 36(12): 15-18. (In Chinese)

[28] Bozena Seredynska-Sobecka. Removal of Humic Acids by the Ozonation-Biofiltration Process [J]. Desalination, 2006,198 (1/3): 265-273.

[29] Goel S, Hozalski R M, Bouwer E J. Biodegradation of NOM: Effect of NOM Source and Ozone Dose [J]. J AWWA, 1995, 87(1): 90-105.

[30] Greening F. Experience with Ozone Treatment of Water in Switzerland [C]. Andrews G F. Proceedings of 82 ${ }^{\text {th }}$ Ozone world Congress. Zurich, 1987: 49-54.

[31] Lin Wang, Qifang Luo. Study on Degradation of Immobilized Microorganism on Endocrine Disruptor Di-n-butyl Phthalate [J]. China J Public Health. 2003, 19(11): 13021303.

[32] M. Scholz, R.J Martin. Ecological Equilibrium on Biological Activated Carbon [J]. Water. Research. 1997, 31(12): 2959-2968.

[33] R. Narasimmalu, M. Osamu, I. Norifumi, et al. Variation in Microbial Biomass and Community Structure in Sediments of Eutrophicbays as Determined by Phospholipid Ester Linked Fatty Acids [J]. Applied and Environment Microbial.1992, 58(2): 562-571.

[34] G. Collins, A. Woods, M. H Sharon, et al. Microbial Community Structure and Methanogenic Activity during Start-up of Psychrophilic Anaerobic Digesters Treating Synthetic Industrial Wastewaters [J]. FEMS Microbiology Ecology. 2003, 46(1): 159-170. 
[35] D.C Ellwood. Adhession of Microorganisms to Surfaces. London: Academic Press. 1979: 62-78.

[36] D.C Savage, M. Fletcher. Bacterial Adhesion: Mechanisms and Physiological Significance [J]. New York: Plenum Press. 1985: 197-206.

[37] J. David, Pernitsky, R. Gordon, et al. Recovery of Attached Bacteria from GAC Fines and Implications for Disinfection Efficacy [J]. Water Research. 1997, 31(3): 385-390.

[38] Y. Takeuchi, Y. Suzuki, K. Mochidzuki. Biological Activated Carbon Treatment of Organic Water Containing Heavy Metal Ions at a High Salt Concentration [J]. Process. SCEJ Kusyu Regional Meeting. 1994: 125-126.

[39] R.Ahmad, A.Amirtharajah. Detachment of Particals during Biofilter Backwashing [J]. Journal AWWA. 1998, 90(12):74-85.

[40] V.D Kooij. Determining the Concentration of Easily Assimilable Organic Carbon in Drinking Water [J]. Journal AWWA. 1992, 74(10): 540-545.

[41] Y. Liu, Q.D Wang. Surface Modification of Biocarrier by Plasma Oxidation-Ferric Ions Coating Technique to Enhance Bacterial Adhesion [J]. Journal of Environmental Science and Healthy. 1996, (3): 869-879.

[42] LeChevallier, M.W Welch. Full-Scale Studies of Factors Related to Coliform Regrowth in Dinking Water [J]. Applied and Environmental Microbial. 1996, 62(7): 2201-2211.

[43] Guangzhi Wang. Study on Biological Stability Control of Dominant Bacteria in Immobilization Biological Activated Carbon [J]. Dissertation for the Doctoral Degree in Engineering, June, 2008, China.

[44] J.G Jacangelo. Selected Processes for Removing NOM: An Overview [J]. Journal AWWA. 1995 (1): 64-77.

[45] D. Susan, Richardson. Disinfection By-products and Other Emerging Contaminants in Drinking Water [J]. Trends in Analytical Chemistry. 2003, 22(10): 255-275.

[46] Jun Ma, Tao Zhang, Zhonglin Chen, Minghao Sui, Xueyuan Li. Pathway of Aqueous Ferric Hydroxide Catalyzed Ozone Decomposition and Ozonation of Trace Nitrobenzene [J]. Environmental science. 2005, 26(2): 78-82.

[47] Laisheng Li, Wanpeng Zhu, Zhonghe Li. The Removal of Difficult Degradation Pollutants by catalytic $\mathrm{O}_{3}$ catalytic and adsorption technology [J]. China water \& waste water. 2002, 18(5): 23-25.

[48] T.A Bellar. The Occurrence of Oraganhalids in Chlorination Drinking Water [J]. J.Am. Water work Assoc. 1974, 66(12): 703.

[49] J.C Kruith, A.J Veer, J.P Hoek. Ozonation and Biological Activated Carbon in Dutch Drinking Water Treatment [J]. Regional Conference on Ozone. Netherland. 1996: 85-101.

[50] He Dao-hong, Gao Nai-yun, Zeng Wen-hui, et al. Biofilm Colonization in Advanced Treatment of Drinking Water Using Biological Activated Carbon Process[J]. Industrial Water \& Wastewater, 2006, 37(2): 16-19.(In Chinese)

[51] Bożena Seredyńska-Sobecka. Removal of Humic Acids by the Ozonation-biofiltration Process [J]. Desalination, 2006, 198(3): 265-273.

[52] C.H. Liang, P.C. Chiang, E.E. Chang. Systematic Approach to Quantify Adsorption and Biodegradation Capacities on Biological Activated Carbon following Ozonation [J]. Ozone Science \& Engineering, 2003, 25: 351-361. 
[53] Qing Tian, Jihua Chen. Application of Bioactivated Carbon (BAC) Process in Water and Wastewater Treatment [J]. Environmental Engineering, 2006, 24(1): 84-87. (In Chinese)

[54] Pengkang Jin, Dewang Jiang, Xiafeng Zhang, Xiaochang Wang. Study on the Characteristics of Microorganism Distribution in Biological Activated Carbon Following Ozonation [J]. Journal of Xi'an University of Architecture and Technology, 2007, 39(6): 829-833.(In Chinese)

[55] Wang Min, Shang Haitao, Hao Chunbo, Luo Peng, Gu Junnong, Diversity and Bacteria Community Structure of Activated Carbon Used in Advanced Drinking Water Treatment, [J].Environmental Science, 2011, 32(5): 1497-1504. (In Chinese)

[56] Liang C H, Chiang P C, Chang E E. Systematic Approach to Quantify Adsorption and Biodegradation Capacities on Biological Activated Carbon Following Ozonation[J]. Ozone Science \& Engineering, 2003, 25(5): 351-361.(In Chinese)

[57] He Daohong, Gao Naiyun, Zeng Wenhui, et al. Biofilm Colonization in Advanced Treatment of Drinking Water Using Biological Activated Carbon Process [J]. Industrial Water \& Wastewater, 2006, 37(2): 16-19. (In Chinese)

[58] Qiao Tiejun, Zhang Xiaojian. In-situ Substrate Uptake Rate Method for Measuring Microbial Activity [J]. China Water \& Wastewater, 2002, 18(7): 80-82.

[59] Bozena S S. Removal of Humic Acids by the Ozonation-biofiltration Process [J]. Desalination, 2006, 198(13): 265-273.

[60] Pengkang Jin, Jianjun Xu, Dewang Jiang, Xiaochang Wang. Quantifying Analysis of the Organic Matter Removal by Adsorption and Biodegradation on Biological Activated Carbon Following Ozonation [J]. Journal of Safety and Environment, 2007, 7(6), 22-25. (In Chinese)

[61] Gao Yanhui, Gu Guowei. Water Pollution Control Engineering [M]. Beijing: Higher Education Press, 1999.

[62] WANG xiaochang, ZHANG chengzhong. Environmental Engineering Science [M]. Beijing: Higher Education Press, 2010.

[63] Qiao Tiejun, Sun Guofen, Study on Microbial Safety of Ozone/Biological Activated Carbon Process [J]. China Water and Wastewater, 2008, 24(5): 31-39.(In Chinese)

[64] Zhang Jinsong, Qiao Tiejun. Water Quality Safety and Safeguard Measures of Ozonebiological Activated Carbon Process [J].Water and Wastewater Treatment, 2009, 35(3): 9-13.(In Chinese)

[65] Qiao Tiejun, Zhang Xihui, Water Quality Safety of Ozonation and Biologically Activated Carbon Process in Application [J].Environment Science, 2009, 30(11): 33113315.(In Chinese)

[66] Coleman W.E., Munch J.W., Ringhand H.P., Kay-lor W.H. and Mitchell D.E., “Ozonation/Postchlori-nation of Humic Acid: A Model for Predicting Drinking Water Disinfection by-Products". Ozone Sic. \& Engi-neering, 1992, 14, 51-69.

[67] Kurokawa Y., Maekawa A., Takahashi M. and Hayashi Y., "Toxicity and Carcinogenicity of Potassium Bromate-A New Renal Carcinogen", Environ. Health Perspect., 1990, 87, 309-335.

[68] X. C. Wang, The Byproducts of Ozonation [J]. Water and Wastewater Treatment, 1998, 24(12): 75-77.(In Chinese)

[69] Zhangbin Pan, Baorui Jia. The Water Quality Safety Oz-BAC Process: A Review [J]. City and Town Water Supply, 2010, 2, 67-70. (In Chinese) 